\title{
VENDER LA ENFERMEDAD: \\ ANÁLISIS DEL DISCURSO PUBLIPROPAGANDÍSTICO EN YOUTUBE DE PACO SANZ, EL HOMBRE DE LOS DOS MIL TUMORES
}

\author{
Sara RoBles Ávila \\ Universidad de Málaga (España)
}

\section{RESUMEN}

El caso del estafador Paco Sanz, el hombre de los dos mil tumores, tuvo una gran repercusión mediática entre los años 2011 y 2017. Supuestamente sufría una enfermedad incurable y, con grandes dosis de dramatismo, se exhibía en su canal de YouTube para recaudar fondos para un tratamiento en EE. UU. y así poder curarse. Utilizando mensajes manipuladores y, según se denuncia, fraudulentos, además de recursos propagandísticos y publicitarios con los que engañar al auditorio, obtuvo una elevada suma de dinero procedente de un público sometido a su decir. En este trabajo realizamos un estudio de su discurso, de su hablar particular, entendiendo que con su palabra expresiva y bien seleccionada desarrolla una actividad de abuso de poder sobre el receptor.

PALABRAS ClAVE: publicidad; propaganda; discurso oral; enfermedad; estafa.

\section{AbSTRACT}

The case of scammer Paco Sanz, the so-called man with the 2.000 tumours, reached an enormous impact in the press between 2011 and 2017. Supposedly, he suffered from an incurable disease and, with a lot of dramatism, he showed his situation in his own YouTube channel, where he demanded economic support for a healing treatment in the US. Using manipulative, fraudulent messages and tools from propaganda and publicity, he lied to his followers and obtained a big amount of money. In this piece of research, we will concentrate on the discourse built by Paco Sanz, because we consider that the skilful way in which he uses language reflects an abuse of power on his audience.

KEYWORDS: publicity; propaganda; oral discourse; disease; fraud. 


\section{Introducción. Paco SAnZ, la historia de un Engaño}

En 2011 salta a los medios de comunicación ${ }^{1}$ el caso de Paco Sanz -en adelante PS-, un paciente de una enfermedad rara de origen genético denominada síndrome de Cowden, caracterizada por la aparición de tumores por todo el cuerpo que, aunque benignos, pueden mutar y resultar letales. El enfermo, que se presenta desde sus primeras intervenciones en un supuesto estado crítico y temeroso de un desenlace fatal de su enfermedad, es el encargado de organizar toda una sólida infraestructura fraudulenta en torno a una enfermedad que en verdad padece, pero que en modo alguno reviste el peligro que exhibe y magnifica públicamente. Valiéndose del argumento de una más que probable curación en EE.UU. gracias a un tratamiento experimental para el que necesita de apoyo económico ${ }^{2}$, entre finales de 2010 y marzo de 2017 el estafador consiguió recaudar alrededor de $350000 €$ en donaciones de más de 14000 personas, en la que se ha considerado una de las mayores estafas de esta naturaleza ocurridas en España. En 2017 fue detenido y acusado de tres delitos: blanqueo de capitales, apropiación indebida y estafa. Quedó en libertad provisional y en febrero de 2021 la sentencia firme de la Audiencia Provincial de Madrid condenó a PS a dos años de cárcel y al pago de casi $37000 €$ por estafa ${ }^{3}$.

El caso de PS, el hombre de los dos mil tumores, como él mismo se presentó ante la opinión pública, se convirtió en una historia mediática que no solo difundieron los medios de comunicación y a la que dieron su apoyo famosos de distintas áreas ${ }^{4}$, sino que el mismo protagonista desplegó mediante toda una serie de prácticas de exhibición pública con el objetivo de difundir su enfermedad y conseguir la benevolencia del auditorio traducida en donaciones económicas. Gracias inicialmente a la redes sociales Facebook y Twitter, y más tarde, a la creación de un canal propio en YouTube (<https://www.youtube.com/user/pacopsanz1911>) -clausurado en la actualidad- al que denominó sin ambages Paco Sanz, y acompañó del subtítulo sugerente a modo de eslogan publipropagandístico Una vida de sueños,

${ }^{1}$ La primera referencia a Paco Sanz que hemos rastreado en los medios de comunicación corresponde al programa Gente, de TVE1, del día 13 de enero de 2011. A partir de entonces la noticia sobre su caso se viralizó en todos los medios y tuvo una repercusión mantenida en el tiempo debido a los continuos impactos informativos.

${ }^{2}$ Pues asegura que solo dispone de una pensión por incapacidad absoluta que no le permite sufragar los gastos de viaje y la supuesta sanación.

${ }^{3}$ Una cantidad muy inferior a la estafada, ya que no se ha podido localizar a todos los pequeños donantes.

${ }^{4}$ Entre los famosos que le brindaron su apoyo a través de distintas acciones se encuentran el youtuber AuronPlay; Pedro García Aguado, exdeportista profesional y presentador de diversos programas de televisión; el humorista Santi Rodríguez; y el cantante Driak, entre otros muchos. 
una vida de luch $a^{5}$, así como a sus frecuentes apariciones en prensa, en programas de radio y televisión, el estafador, manejando con maestría comunicativa los diferentes campos de acción (Cortés 2012) con sus procesos diferenciados según los géneros (entrevista, discurso en las redes sociales virtuales, vídeos, etc.), llegó a ser lo que fue. A través de los medios y con el fin de lucrarse contaba su historia y exhibía su dolor y su angustia ante una muerte acechante, pero también sus ganas de vivir y su esperanza en la curación, que hacía depender de un auditorio sensibilizado por la elocuencia y la vehemencia de este enfermo que urdía con argucias fraudulentas una estafa colosal, según las denuncias que más tarde interpusieron contra él particulares y colectivos. Sin duda, fue el citado canal de YouTube, creado en febrero de 2010, el que dimensionó el caso, y le permitió a Sanz compartir contenidos audiovisuales en forma de vídeos testimoniales que él mismo grababa de manera amateur, gracias a las posibilidades que le brindaba la web 2.0, y con los que en una rotunda primera persona daba a conocer su día a día, el supuesto empeoramiento de su enfermedad ${ }^{6}$, sus cuitas por la falta de atención de las autoridades, y solicitaba la colaboración económica de los oyentes.

Basándonos en un corpus de cuarenta y seis vídeos ${ }^{7}$ alojados en su canal de YouTube y fechados entre marzo de 2011 y mayo de 2016, en este trabajo nos proponemos analizar el discurso oral publipropagandístico que PS construye para dirigirse a sus seguidores ${ }^{8}-2670$ a fecha de la redacción de

${ }_{5}^{5}$ Este subtítulo lo toma del libro que escribió sobre su vida M. Hervas Abad (2015).

${ }^{6}$ Los vídeos testimoniales estaban clasificados por orden cronológico invertido y hacían un total de 114. Estos se iniciaban en EE.UU. en marzo de 2011 y el último de ellos correspondía a mayo de 2016.

${ }^{7}$ El conjunto de vídeos del canal, un total de ciento catorce, presenta bastante heterogeneidad en la temática: se detecta, por una parte, un grupo compacto que constituyen el que podemos llamar núcleo duro, más numeroso, dedicado a la presentación de su enfermedad, y especialmente a su evolución tanto física como anímica a través de testimonios periódicos; y, por otra, hallamos vídeos musicales, humorísticos, de escenas de su vida cotidiana, doméstica, donde comparte protagonismo con artistas, presentadores, cantantes, etc. Ante tal variedad, la selección de los vídeos para este trabajo se ha visto determinada por la relevancia de la información que ofrecía el emisor y que se materializa en la producción de un discurso publipropagandístico en torno a su enfermedad, su estado y su solicitud más o menos directa de ayuda. Por tanto, los vídeos que conforman nuestro corpus hacen un total de cuarenta y seis, y representan el eje central de la puesta en escena de PS y de la cuestación al oyente.

${ }^{8}$ Los cuarenta y seis vídeos de nuestro corpus fueron transcritos y digitalizados para operar con ellos de manera informática. Se ha transcrito fielmente cada una de las piezas, de modo que los errores de PS -de toda naturaleza-, los titubeos, las vacilaciones, etc., se han recogido sin enmendar. Hemos empleado documentos .txt porque es el formato con el que trabaja el programa de AntConc (3.4.4), que nos ha permitido obtener las listas de palabras empleadas en el discurso de PS, y así observar la singularidad de su hablar, los índices de frecuencia léxica, además de realizar búsquedas, delimitar tendencias, obtener concordancias, etc. Aunque esta investigación es de naturaleza cualitativa e interpretativa, el análisis cuantita- 
este texto, pero muchos más en el momento cronológico de su emisión; lógicamente antes de descubrirse la estafa-. Para ello, prestaremos especial atención a los rasgos prototípicos de su hablar particular y a las estrategias argumentativas, persuasivas y manipuladoras de unos mensajes creados para llamar la atención de su auditorio, conmoverlo y dirigirlo a la acción estratégica que ha diseñado con el único objetivo del enriquecimiento personal. En nuestro acercamiento utilizaremos planteamientos de los Estudios Críticos del Discurso (van Dijk 2009) ${ }^{9}$, así como de la Teoría de los Marcos Cognitivos (Lakoff 1996 y 2004); además, dado que el registro que emplea este emisor particular es intencionalmente coloquial, nos apoyaremos en estudios sobre el tema que nos permitan interpretar los hechos lingüísticos y sus intenciones comunicativas.

Gráfico. Perspectivas de análisis del discurso de PS

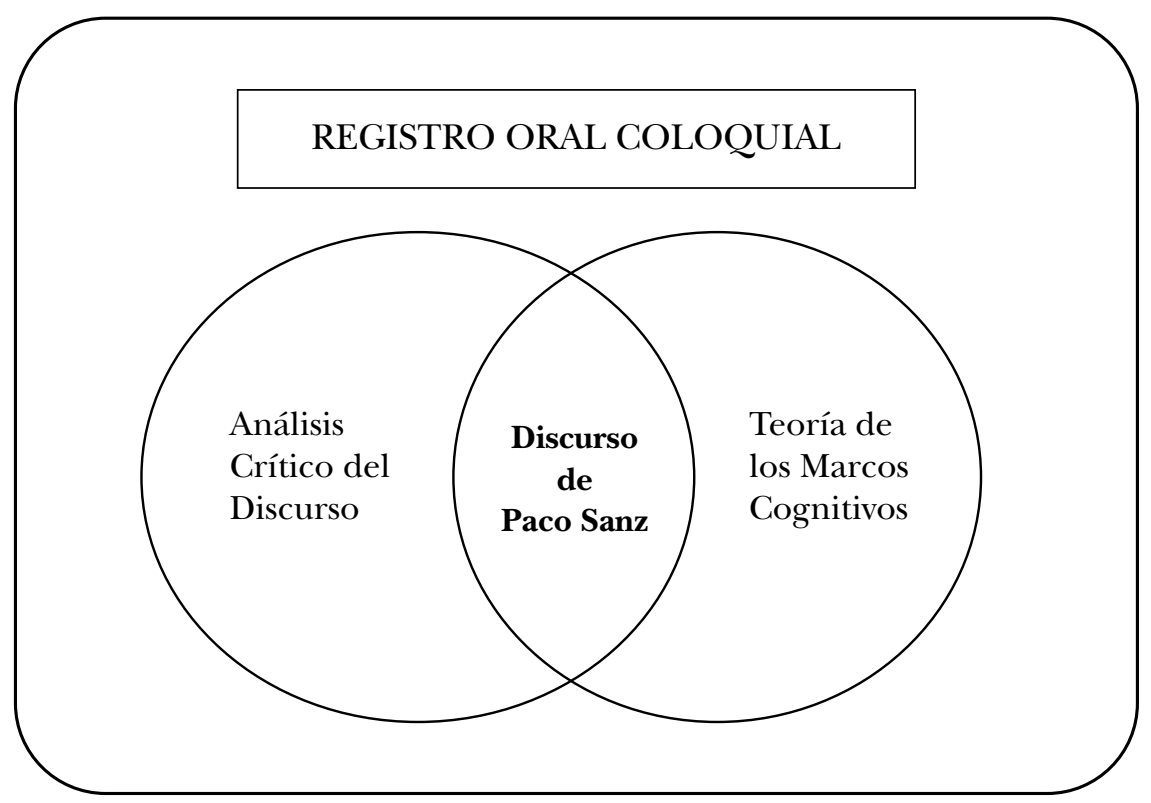

tivo nos permitirá reflexionar sobre ciertos hechos lingüísticos que nos resultan especialmente significativos en nuestro estudio, y medir su frecuencia de uso en el corpus de investigación. El corpus de vídeos arroja un total de 33052 words tokens y 3196 words types.

${ }^{9}$ El propio van Dijk (2009: 21) prefiere cambiar la denominación de Análisis Crítico del Discurso por Estudios Críticos del Discurso principalmente, porque los Estudios Críticos del Discurso no son un único método de análisis del discurso, sino que utilizan cualquier método que sea pertinente para los objetivos de los proyectos de investigación, y sus métodos de estudio son los que se emplean en los estudios del discurso. 


\section{Cuando la ENFERMEDAd ES MERCANCÍA: PUblicidAd y PROPAGANDA EN LOS MENSAJES DE PS}

Las noticias periodísticas y los anuncios publicitarios relacionados con las enfermedades $\operatorname{raras}^{10}$ apenas tienen cabida en los medios de comunicación; su grado de ocurrencia es bastante escaso ${ }^{11}$-limitado, por lo general, a los períodos coincidentes con distintas celebraciones (Sánchez Hernández 2016: 242)-, por lo que su capacidad para ejercer una verdadera influencia social se ve muy reducida. Además, cuando aparecen, con frecuencia tiende a desvirtuarse la función informativa y explicativa sobre las propias enfermedades -en buena parte motivado por la falta de especialización de los periodistas en cuestiones del ámbito de la salud (Chimero 2004 y González Borja 2004) - sustituyéndose por todo un despliegue de dramatismo y de espectacularidad asociados a ellas que los medios replican en una secuencia ecoica (Álvarez Villa et al. 2014: 2) sin solución de continuidad y, en consecuencia, sin cuestionarse la veracidad de lo que transmiten, lo que alimenta potencialmente el fraude y las estafas, como en el caso que nos ocupa. Ante esta situación de escasa presencia en la comunicación pública, asociaciones y pacientes de estas enfermedades de baja prevalencia se valen de los medios electrónicos para darse a conocer, lograr una mayor visibilidad y solicitar apoyos, tratando de legitimarse y autoafirmarse como «grupos capaces de desarrollar funciones socialmente útiles y de contribuir responsablemente a la mejora de las personas afectadas» (Bañón 2007: 223).

PS irrumpe de manera individual en los medios de comunicación, en las redes sociales y en YouTube como representante de una asociación que lleva su propio nombre y que supuestamente aglutina a los pacientes que sufren el síndrome de Cowden. Como si se tratara de un vendedor charlatán de otros tiempos, que maneja sabiamente estrategias hipnotizadoras para anular la conciencia de sus seguidores gracias a la plataforma de exhibición pública que le ofrecen los vídeos alojados de manera gratuita en YouTube ${ }^{12}$,

${ }^{10}$ Se considera enfermedad rara aquella que tienen una incidencia inferior al 5 por cada 10000 habitantes. Según la Organización Mundial de la Salud (OMS), existen a día de hoy alrededor de 7000 enfermedades raras que afectan al $7 \%$ de la población mundial.

${ }^{11}$ Bañón (2007, 2013 y 2015) ha venido realizando interesantes contribuciones al estudio de las enfermedades raras desde la perspectiva del Análisis Crítico del Discurso. En lo referente a la representación social de estos enfermos en los medios de comunicación considera que se trata de un colectivo minoritario con escasa capacidad para ejercer una influencia suficiente en los asuntos políticos y sociales, por lo que han sido sistemáticamente excluidos de los foros de discusión más relevantes (Bañón 2007: 222).

${ }^{12}$ López Villafranca (2015: 1045), en su estudio sobre las campañas de comunicación de los pacientes con enfermedades raras, otorga a YouTube la consideración de plataforma idónea para lanzar campañas audiovisuales sobre salud, aunque ya advierte de que puede resultar poco fiable, con información dañina, distorsionada, conductas poco saludables, etc. 
PS crea un discurso de poder -específicamente de abuso de poder, de dominación ${ }^{13}$ - pero encubierto, opaco, mediante prácticas comunicativas de manipulación y desinformación (el engaño, la mentira y la simulación), donde a través del micronivel de sus textos personales, de su decir particular en los vídeos podemos identificar los aspectos típicos del macronivel de la sociedad, tales como aquellos de los grupos de poder y sus relaciones de dominación. Si los Estudios Críticos del Discurso (van Dijk 2009: 20) se encargan de analizar los abusos de poder y la desigualdad para luchar contra las clases dominantes en favor de los oprimidos ${ }^{14}$, en nuestro caso aplicamos esta metodología en la lucha contra el fraude, la falacia y el engaño que conforman la estrategia manipuladora de PS en favor de los estafados que, por su buena voluntad y su compasión, han sufrido los abusos. A nivel microtextual, el discurso del poder y del fraude de PS oscila entre un objetivo fingido aparentemente altruista de ayuda a una causa colectiva de la que él es representante ${ }^{15}$ («Si queréis echar una mano a la lucha contra el cáncer...», vídeo 7) y un interés exclusivamente personal basado en su curación ( Por favor, ayudadme y no os olvidéis de mí [...]. Yo en estos momentos necesito...», vídeo 46).

En el uso del lenguaje y en la construcción del discurso, PS despliega toda una serie de mecanismos de atracción del oyente hacia lo dicho como pueden ser el empleo de ciertas estructuras, la entonación, la selección léxica, la preferencia por determinadas clases de palabras y expresiones, el empleo de fórmulas apelativas dirigidas a un receptor pasivo verbalmente, las marcas de cohesión textual específicas, no solo sintácticas (como os he dicho muchas veces, como habéis visto, etc.), las estrategias de intensificación, de repetición, el empleo de figuras retóricas ${ }^{16}$, el tratamiento de la cortesía, etc. El abuso de poder sobre sus seguidores se asienta también en argumentos de ayuda a su causa basados en amenazas: «Acordaros siempre de lo que os digo: si queréis echar una mano a la lucha contra

13 Entendemos dominación en el sentido que expone van Dijk, es decir, la forma de abuso de poder que «implica la dimensión negativa del abuso y también la dimensión de desigualdades, injusticia e inequidad, es decir, todas las formas de acciones y situaciones ilegítimas» (2009: 41).

${ }^{14}$ Consecuente con esta perspectiva de análisis (van Dijk 2009: 27), nuestra investigación toma partido en favor del grupo dominado, engañado, al que PS dirigía sus mensajes impositivos.

${ }^{15}$ Los fragmentos que ejemplifican los fenómenos analizados aparecen acompañados de un número que corresponde al vídeo del que proceden. La lista de vídeos con su número identificativo queda recogida al final de este trabajo.

${ }^{16}$ Los Estudios Críticos del Discurso ponen el énfasis en «aquellas propiedades del discurso que están característicamente asociadas a la expresión, reproducción o impugnación del poder social de los oradores o escritores, en su condición de miembros de los grupos dominantes» (van Dijk 2009: 24). 
el cáncer, si quieres echar una mano a aquí porque nunca sabes cuándo puede llamar a nuestra puerta, y lo digo siempre, por favor, entrar en...» (vídeo 7).

Por tanto, se trata de mecanismos que comprenden desde la utilización de estímulos coloquiales para que el auditorio participe indirectamente en forma de adhesión a su causa, hasta la provocación del asentimiento. El alocutor manifiesta su abuso de poder, su posición dominante frente a sus seguidores sobre los que ejerce su presión, lo que implica que estos textos provocan, sin duda, unas consecuencias sociales.

Desde la Teoría de los Marcos Cognitivos (Lakoff 1996, 2004, 2008a y 2008b) podemos interpretar los mensajes de PS en relación con la recepción que de ellos hacen sus seguidores al decodificarlos y al someterlos, por tanto, al filtro del marco -entendido como contexto- que le da sentido. Dado que los marcos son estructuras mentales que conforman nuestro modo de ver el mundo y que dirigen nuestras metas y objetivos, nuestros planes, organizan la forma como tenemos que actuar para conseguir nuestros objetivos (Lakoff 2004: 4), PS aprovecha la cultura común y el conocimiento compartido con su auditorio para apelar a unos marcos profundos (Lakoff 2008a: 61-62 y 2008b: 107) -aquellos que, en su caso, activan la empatía y refuerzan valores de solidaridad-que se materializan en el empleo de otros marcos de superficie, más simples, asociados a palabras, sintagmas y agrupaciones léxicas de distinta naturaleza, como los eslóganes ${ }^{17}$. Este alocutor particular realiza una selección léxica que lleva a un marco cognitivo de significados y connotaciones persuasivos y manipuladores de la voluntad de su auditorio. Un buen ejemplo lo representa el empleo de eufemismos que permiten nombrar lo innombrable sin precisarlo, lo cual resulta muy rentable en la comunicación (Vigara Tauste 1996: 29), como sucede con el eufemismo fraudulento reflexiones, que remite a un marco profundo de naturaleza filosófica, de pensamiento crítico, y que es utilizado por PS con carácter disuasorio para definir sus mensajes de YouTube, cuando en realidad se trata de auténticas cuestaciones al auditorio ( Soy una persona que quiere hacer una pequeña reflexión porque siente que su vida se escapa, siente que está perdiendo la batalla», vídeo 13); aunque insista en aparentar que no lo son ( «yo no estoy pidiendo dinero, no estoy pidiendo nada, estoy solamente haciendo una reflexión», vídeo 40).

La selección léxica es la herramienta fundamental en el discurso persuasivo (Santiago Guervós 2008: 121) y resulta clave en el de abuso de poder

\footnotetext{
${ }^{17}$ Para Lakoff (2008a: 61-62) los marcos profundos definen el sentido común global del ser humano y constituyen una cosmovisión moral; aparecen representados por los marcos de superficie gracias al empleo del lenguaje. Sin esos marcos profundos, los de superficie no podrían salir a la luz, no se entenderían.
} 
en tanto que a través de ella PS escoge también los correspondientes marcos de superficie y dirige la interpretación, los procesos de decodificación y de inferencia. Se trata de palabras marcadas que estimulan marcos profundos determinados mediante los cuales influir en el oyente de manera inconsciente y que se organizan en dos polos que representan en esencia la paradoja constante de todos sus mensajes: un polo positivo, correspondiente a un discurso afirmativo, que remite a marcos profundos relacionados con la solidaridad, el optimismo, la felicidad, el disfrute de la vida («el canal Paco Sanz es un canal para que la gente tenga alegría, tenga ganas de vivir», vídeo 43); y un polo negativo, asociado a marcos profundos que tienen que ver con la enfermedad, con el dolor, con la necesidad de pedir ayuda, apoyo económico porque se encuentra desatendido («Mi cuerpo me duele y yo contra el dolor no puedo", vídeo 45).

El discurso de poder de PS, fundado en marcos profundos de empatía y solidaridad con el dolor que padece, si bien en sus primeros momentos se podría calificar de parcialmente informativo -porque apenas nos ofrece datos explicativos sobre el síndrome de Cowden, la enfermedad que sufre $^{18}$, las consecuencias de esta, su anodina rutina diaria, todo ello expresado en un tono lastimero y emotivo, aunque exhibido con un fingimiento impostado en una apariencia de optimismo y positividad poco creíble-, ocultan una intención ilocutiva y perlocutiva de poder y manipulación sobre su audiencia mediante la cual pide ayuda urgente -que se va haciendo desesperada conforme pasan los meses- para su tratamiento médico. Así, con el discurrir del tiempo y debido a la astuta selección de las formas lingüísticas y la planificada puesta en escena se evidencia un viraje al drama y a la desesperación que paulatinamente va aumentando en intensidad hasta llegar a intimidar y agredir al interlocutor por su crudeza, advirtiéndose en mayor medida el discurso de dominio:

La verdad que muchas veces esta lucha contra el cáncer, esta lucha contra toda esta enfermedad de mierda que tengo, una palmadita en la espalda hace mucho. Un «vamos, todos somos uno» hace mucho. Y la verdad que me he sentido solo, me he sentido olvidado, me estoy sintiendo olvidado. Este mes, por ejemplo, llevo seis mensajes (vídeo 40).

\footnotetext{
${ }^{18}$ Solo ofrece algunas pinceladas de la enfermedad en los primeros vídeos: «El síndrome de Cowden, como os he dicho antes, el cáncer genético son sinónimos, es una malformación que tenemos en un gen, como os he dicho antes, es el gen PTEN: qué nos provoca: nos provoca tumores en todas las partes blandas del cuerpo, más aparte en la cara, en las manos, en la cabeza; son tumores benignos pero, como no tenemos esa protección natural, se convierten en tumores malignos. Entonces en España no existe ningún fármaco, ningún tratamiento, nada de nada, de nada. Entonces qué es lo que hay que hacer: pues tratamiento preventivo y, si te lo puedes permitir, irse a los EE.UU.» (vídeo 1).
} 
Por tanto, en la práctica comunicativa de PS la manipulación que ejerce sobre sus seguidores presenta tres aspectos caracterizadores (Nettel y Roque 2012: 58): el disimulo de la intención de manipular, la presión o coacción y, como consecuencia, la obstrucción de la libertad de la persona para decidir, en este caso.

Por su intención ilocutiva y sus aspectos formales todas las intervenciones que PS sube a su canal se deben considerar publipropagandísticas ${ }^{19}$ de una mal entendida publicidad social ${ }^{20}$ que, en realidad, enmascara un discurso tendencioso e impositivo propio del ámbito ideológico, político y comercial con el que apelar al interlocutor, conmoverlo, influir en él y conseguir su apoyo en forma de colaboración para una causa aparentemente solidaria.

El poder demostrativo de la imagen se reconoce como estrategia en su puesta en escena: siempre en primer plano, mostrándose con las aparentes secuelas de su enfermedad -a veces con gorra y gafas de sol que, cubriendo su cabeza y sus ojos respectivamente, según sus palabras palían su malestar, especialmente cuando se expone a la luz solar- y son argumentos que apoyan la veracidad de lo que cuenta ${ }^{21}$. Las grabaciones se realizan general-

${ }^{19}$ Un sector de la crítica diferencia la publicidad de la propaganda basándose fundamentalmente en el carácter ideológico de la propaganda -como Méndiz Noguero señala (2008: 53), esta nace ligada al mundo de las ideas- que no comparte la publicidad (Herreros 1989; Pineda Cachero 2007a y 2007b; Huici Módenes 1994 y 1996; Huici Módenes y Pineda Cachero 2004; Rey 1999 y 2005; y, en otro sentido más completo, Méndiz Noguero 2008, entre otros). También Eguizábal añade que, más allá de los motivos ideológicos que sustentan los actos propagandísticos, destaca «su tendencia a la simulación de sus intenciones y de sus medios, frente a la vocación pública y abierta de la actividad anunciadora y publicitaria» (1998: 14). Nosotros consideramos, en la línea de investigadores como Gutiérrez Ordóñez (1997 [2000]), una relación estrecha entre ambas prácticas en tanto la publicidad, especialmente la comercial -no la social ni la institucional- es, de base, una clase de propaganda capitalista, además de que muchos productos y, en especial, sus marcas representan valores relacionados con una forma de ser y de pensar propios de la propaganda, de modo que lo comercial se une a lo ideológico y quien compra cierto producto está adquiriendo también los valores, esos significados asociativos que lo acompañan. Es lo que ocurre con marcas consagradas como Burberry, Jaguar, Chanel o Dior, que añaden a los productos toda una serie de connotaciones positivas muy valoradas por los consumidores (Robles Ávila 2005a: 128-133).

${ }^{20}$ Donde debería primar lo informativo antes que comprometer al público con un acto concreto. La publicidad social aparece definida por Kotler y Roberto como «un esfuerzo organizativo dirigido por un grupo (el agente de cambio) que intenta persuadir a otros (los adoptantes objetivos) de que acepten, modifiquen o abandonen ciertas ideas, actitudes, prácticas y conductas» (1992: 7).

${ }^{21}$ «La imagen cumple una función designativa de la realidad: aparentemente muestra directamente el mundo sin que se interponga nada entre la imagen y el sujeto que mira, de ahí que sea un instrumento valiosísimo de autentificación, proporcionando un efecto de realidad (y es que la imagen por sí sola responde afirmativamente a la pregunta que se formula implícitamente el que consume la infomación: ¿existe esto? lo estoy viendo, luego existe)». (Méndez y Leal 2007: 596). 
mente en escenarios domésticos, en su casa o alrededores y, valiéndose de un discurso oral espontáneo, no leído, construido sobre la marcha -quizá a partir de algunas ideas apuntadas-, en un registro familiar, para crear la empatía de su auditorio, cumple en mayor o menor medida todos los rasgos del denominado prototipo de lo coloquial (Briz 1995; Grupo Val.Es.Co. 2002) o constelación comunicativa coloquial (López Serena 2007: 185), en tanto comprende:

1. una relación social estrecha que el hablante establece con el interlocutor, a pesar de la distancia y del desconocimiento que tienen el uno del otro -como sucede en el discurso público en la actualidad (López Serena 2014: 38) - que aumenta conforme pasa el tiempo y se intensifican los contactos comunicativos;

2. cierta relación vivencial de proximidad, ya que tanto PS como sus seguidores comparten buena parte de los marcos profundos, contextos, saberes y experiencias sobre los temas de sus vídeos;

3. su continuo bombardeo en YouTube genera un sentimiento de cotidianidad en el marco espacial de la Red;

4. una temática no especializada, con el relato de cuestiones del día a día de su vida y de la evolución de su enfermedad;

5. la espontaneidad y la escasa planificación producen una sensación de naturalidad que aumenta conforme avanza la comunicación;

6. el fin interpersonal o socializador genera la confianza entre los participantes en el acto comunicativo y, con ello, una mayor emotividad y expresividad (Briz 2010: 126).

La ausencia de planificación propia del registro coloquial, que provoca que PS vaya actualizando el sentido de su mensaje improvisadamente, se detecta a lo largo de todas sus intervenciones en sus continuos titubeos, anacolutos, deficiencia e incluso incorrecciones formales que denotan la prevalencia de la comunicabilidad (Vigara Tauste 1996: 23) por encima de la corrección.

Y, asentado en el registro coloquial, con toda la eficacia comunicativa que le aporta, PS es capaz de disfrazar el abuso de poder que ejerce sobre su auditorio, y construye su peculiar mensaje publipropagandístico desplazado de los cánones establecidos. De manera que, en un continuum del habla (Briz 1996: 16) entre los polos de mayor coloquialidad a mayor formalidad, el de Sanz se colocaría en el ámbito de lo puramente coloquial seguido del propagandístico (especialmente si es político) y en un espacio más alejado de lo coloquial y, por tanto, más próximo a lo formal, se ubicaría el discurso publicitario más fresco y natural de determinados bienes y servicios, aquel que busca un mayor acercamiento al potencial comprador 
a través del habla, y que se ha de entender, no obstante, como una recreación artificial -más o menos lograda- de lo coloquial, por lo que tiene de planificada cualquier acción publicitaria ${ }^{22}$.

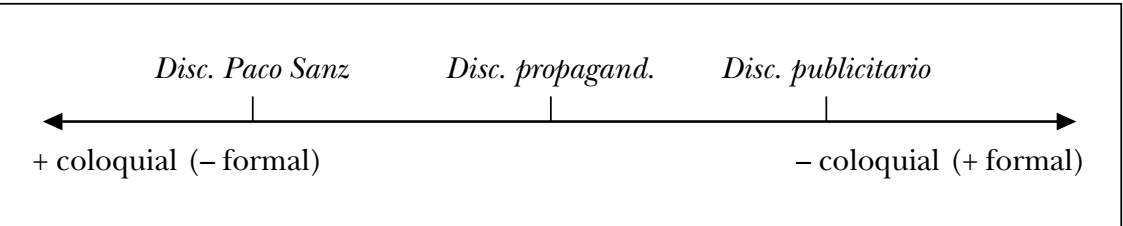

Por su dimensión propagandística los mensajes de PS pueden ser analizados desde la perspectiva de los Estudios Críticos del Discurso (van Dijk 2009) y de la Teoría de los Marcos cognitivos (Lakoff 1996, 2004, 2008a y 2008b). PS ejerce un poder sobre su audiencia basado en el engaño, la mentira y el fraude sobre una enfermedad que exagera y de la que crea un mensaje construido sobre marcos de superficie que remiten a otros profundos de lástima y conmiseración con los que apelar a sus oyentes. El discurso de poder de PS se enmascara en unos marcos profundos invisibles que salen a la superficie en el empleo de un lenguaje $\mathrm{e}^{23}$ persuasivo y manipulador de las voluntades del auditorio. PS sabe que para inducir a sus seguidores a la acción colaboradora no hacen falta argumentos lógicos sino transmitir pasión y apelar a valores solidarios vinculados a marcos profundos almacenados en la conducta humana. Desde esta perspectiva se constata el abuso de poder que ejerce PS en tanto, como un político que exhibe un yo dominante, agita con su discurso a su auditorio incitándolo a hacer algo que provoque una reacción en el destinatario que respalde su planteamiento (Fernández Lagunilla 1999); en concreto, este alocutor trata de vender con sutileza un motivo loable y generoso, como es la necesidad de ayudar a la investigación y el apoyo a las enfermedades raras, y particularmente a la que él padece, escondiendo sus verdaderas intenciones. Ejerce un auténtico control mental sobre los seguidores, conseguido a través de la persuasión y la manipulación que toma como base el conocimiento que este hablante tiene de las debilidades, los sentimientos, y de la respuesta social esperable.

${ }^{22}$ A este respecto, véase el estudio sobre la recreación de lo coloquial en el español de la publicidad, donde se van analizando los rasgos coincidentes y divergentes del lenguaje publicitario con los prototípicos coloquiales (Robles Ávila 2005b).

${ }^{23}$ Lakoff señala: «Language gets its power because it is defined relative to frames, prototypes, metaphors, narratives, images, and emotions. Part of its power come from its unconscious aspects: we are not conscious aware of all that it evokes in us, but it is there, hidden, always at work [...]. Language uses symbols. Language is a tool, an instrument -but it is the surface, not the soul, of the brain» (2008b: 15). 
Además, crea en el interlocutor la necesidad de saber sobre él y seguirlo como si fuera un líder, buscando su fidelización; esto se observa con mayor claridad cuando recupera su canal principal en YouTube, Una vida con Paco Sanz: «Entonces, la verdad, bueno, os dejo la descripción del canal de Una vida con Paco Sanz que ahí es donde podéis ver, como os digo siempre, un ratito lo que es vivir la vida, vivir mis alegrías, vivir mis tristezas, una vida conmigo» (vídeo 44).

Las intenciones estafadoras de PS aparecen encubiertas en un discurso casi filosófico de generosidad mediante el cual trata de imponer a sus seguidores una ideología positiva de la que él mismo participa (marcos profundos) y que se puede resumir en sus ganas de vivir y en la esperanza de un futuro de curación (marcos de superficie: «Con la alegría, con el optimismo y con las ganas de disfrutar de la vida cada momento como si fuera el último», vídeo 21). También la presentación de su libro se convierte en un acto propagandístico al estilo político y al que invita masivamente: «Os lo he dicho antes: invitar a toda la gente que pueda venir día 7 a las siete y media, librería Leo de Valencia; los que no podáis asistir, vamos a hacer un streaming en directo $y$, si no, lo grabaremos y lo subiremos a YouTube» ${ }^{24}$ (vídeo 18).

Pero el de PS es también un discurso publicitario en la medida en que él mismo se convierte en objeto comercial: su enfermedad es el producto que exhibe públicamente y a la vez, en sentido metonímico, él es la enfermedad; en torno a ella crea argumentos con el objetivo de conmover al interlocutor y obtener donaciones económicas. Se puede apreciar con bastante nitidez la evolución en la construcción del discurso, pues, si en sus primeros vídeos solo exponía su situación, explicaba su enfermedad y agradecía a la audiencia su atención, todo ello con un trasfondo propagandístico evidente, a partir del vídeo quinto -que titula Esperanza es sobrevivir (vídeo 5) - instaura la presencia de secuencias de discurso publicitario donde solicita ayuda económica a través de su página web, los SMS, las llamadas telefónicas y, posteriormente, visualizando su videoclip o comprando su libro.

Por lo que se refiere a las modalidades discursivas, en la mayoría de las intervenciones en YouTube se detectan, junto a secuencias textuales (Adams 1991) de naturaleza expositiva (donde informa de su estado o de acontecimientos de su día a día casi en directo), narrativa (cuando relata su historia, su estancia en EE.UU., etc., o simplemente lo que le ha sucedido desde su última intervención), descriptiva (dando detalles generalmente

${ }^{24}$ En otros vídeos, la insistencia en el lugar y la hora del evento se consigue con la repetición: «Es solamente deciros que mañana os espero a todos, ya lo he dicho muchas veces, os espero, la librería Leo de Valencia, mañana os espero, 19:30» (vídeo 20). 
de sus síntomas, de la evolución de su enfermedad, etc.) y dialógica (en una conversación fingida con su interlocutor, como veremos más adelante), fragmentos argumentativos con los que justificar sus peticiones y conseguir los apoyos para cumplir su objetivo de sanarse. Dado que el de PS es un discurso centrado en la acción, resultan menos útiles los argumentos coherentes, racionales y objetivos que las apelaciones emotivas y una puesta en escena impactante:

Y si vas al médico y le dices «me sienta mal la medicación, me encuentro
muy mal cuando me la pinchó esta medicación», y yo me sentaba mejor
ESTO [...]. Y me dice, «Bueno pues si te sienta mal cómpralo» y le digo:
«Sí, con mi pensión, me voy a gastar además de todo el dinero que me he
gastado en medicación me voy a pagar 153 euros más», y que te miren
como diciendo me importa una mierda. Eso te parte por dentro y te parte
el alma. Y lo que quieren es hundir, hundirte moralmente que acabe ya
esta lucha y, por lo menos, sea... un ahorro más porque ya no estarás (ví-
deo 41 ).

Por tanto, las estrategias argumentativas que emplea coinciden en buena medida con aquellas de la publicidad comercial y de la propaganda política. Es una manera de esconder la verdad mediante una retórica perniciosa y manipuladora. Así se constata que sus vídeos están fundados en argumentos basados en la emotividad ${ }^{25}$; al más puro estilo comercial y propagandístico, PS apela a sus seguidores tratando de conmoverlos y buscando su empatía. Los sentimientos que traslada se mueven en torno a dos polos de un mismo eje: la tristeza y la alegría, el dolor y la salud, la amistad y el odio, la compasión y la altivez, la calma y la furia. No obstante, la tendencia preferente es la de mostrar aquellos sentimientos con los que ganarse la benevolencia de su auditorio ( «Siempre tienes que conseguir que tu historia esté viva; el día que no esté viva estarás muerto. Entonces yo intento que ninguno os olvidéis de mí, que nadie se deje de hablar de la historia ya no de la mía, sino de tanta gente que ocurre y que tiene el síndrome de Cowden o alguna enfermedad rara, cualquier persona», vídeo 5).

Los segmentos discursivos de corte más publicitario se van diseminando a lo largo de sus intervenciones, aunque suelen situarse al final de los vídeos, como colofón de cierre y última idea que debe quedar -buscando hacerla memorable- en la mente del auditorio antes de una brevísima despedida. En estos segmentos PS solicita la cuestación, ruega encarecidamente a sus seguidores -incluso valiéndose de forma recurrente de la expresión de petición por favor- que lo ayuden a poder seguir viviendo, arrojando sobre ellos la responsabilidad última de su curación. Al transmitirse por el

${ }^{25}$ Sobre argumentación en la publicidad comercial, véanse García Uceda (1999: 52), Adam y Bonhomme (2000) y Robles Ávila (2007). 
canal oral y en un registro coloquial y familiar -inmediato, cercano social y discursivamente-, estos fragmentos que recogen un acto de habla directivo (Searle 1969 [1990]) ganan en eficacia, aportan una mayor expresividad y no hay cortapisas para dirigirse sin ambages al auditorio: «De verdad, por favor, acordaros siempre de lo que os digo: si queréis echar una mano a la lucha contra el cáncer, si quieres echar una mano a aquí [...], por favor, entrar en <www.ayudapacosanz.com>» (vídeo 7).

Lo publicitario y lo propagandístico se enlazan en segmentos como el que sigue, cuando se presenta como sujeto y objeto del mensaje:

Yo no me gusta echarme flores, yo lo digo, pero es que como para mí sois como una familia, yo os lo estoy haciendo una reflexión: por favor, si queréis ayudarme a que este sueño, a que vuelva a tener de esperanza, a llenar mi gasolina, pero que no sea yo quiero en vez de gasolina súper quiero un gasoil que dure muchos kilómetros que gaste poco y que duren muchos kilómetros. Así que, por favor, podéis entrar en mi web que es... (vídeo 5).

Por tanto, en el decir de PS se imbrican en mayor o menor medida -dependiendo de factores como pueden ser el momento cronológico del vídeo, las intenciones concretas que quiera manifestar, los hechos que relate, etc.- lo propagandístico y lo publicitario, lo ideológico y lo comercial, lo impositivo -casi violento (como diría Méndiz Noguero 2008: 57) propio del discurso de dominación más evidente- y lo seductor. En todo caso, ambas estrategias comparten una serie de rasgos comunes como el objetivo persuasivo y hasta manipulador, la creación de un discurso retórico mediante la elección estratégica de los recursos lingüísticos, y su base argumentativa (Screti 2011), siendo, no obstante, en los vídeos de PS la persuasión y la manipulación de las voluntades ajenas las piezas clave puestas al servicio de un interés lucrativo personal.

\section{RECURSOS PUblipRopagANDÍSTICOS DE ORALIDAD EN LOS VÍDEOS DE PS}

Como se ha comentado, la comunicación más directa que PS establece con sus seguidores es fundamentalmente a través del canal oral de YouTube. Sus vídeos presentan una estructura bastante regular: suelen comenzar con un saludo que se hace entradilla ecoica con leves modificaciones en los 46 vídeos analizados ( Hola, familia, ¿cómo estáis? espero que bien y que la sonrisa os esté acompañando durante todo el día»), avanza con un cuerpo textual de temática variada, donde da cuenta de su día a día, ofrece anécdotas, datos sobre la evolución de su enfermedad, de su estado anímico, etc., siempre orientado a ganarse la benevolencia de los seguidores; y frecuentemente cierra con un discurso propiamente publicitario, en muchos 
casos introducido por un enunciado consecutivo ( «Así que, por favor, podéis entrar en mi página web») con el que pide la colaboración mediante diferentes fórmulas ${ }^{26}$. De este modo, y a pesar de ser un mensaje monológico, PS utiliza recursos propios de la oralidad para simular un diálogo cercano a su audiencia que, aunque ausente en el momento de la enunciación, mantiene el espejismo de una conversación, considerando que la respuesta se va a traducir en el apoyo a su causa, como ocurre en los discursos publicitario y propagandístico ${ }^{27}$. A continuación, analizaremos una serie de rasgos de naturaleza publicitaria y propagandística caracterizadores del discurso de PS.

\subsection{El yoísmo de PS: sujeto propagandístico y objeto comercial}

Lo que resulta más destacable -y también más esperable, a tenor de la propia denominación del canal (Paco Sanz, una vida de sueños, una vida de lucha) - es la subjetividad de su discurso materializada en la preeminencia publipropagandística del yo, su yoísmo, que, como sujeto hablante y, simultáneamente, objeto exhibido para obtener ayuda, se sitúa en el centro de la diana física (siempre dominando el primer plano, salvo en contadas ocasiones) y discursiva, ya que, por lo general, habla a cámara de él mismo, de sus circunstancias y, con menos frecuencia, de su entorno (sus familiares -especialmente de su madre y su novia- amigos, conocidos, enemigos y políticos de su comunidad de los que se queja por su falta de atención a los enfermos que sufren patologías raras). Así queda patente que este hablante impone su yo y trata subjetivamente la información. A lo largo de los 5 años en los que emite sus vídeos, PS va pasando por diferentes etapas mostrando distintas personalidades: influencer de YouTube; coach de otros enfermos a los que alienta y da su apoyo; consejero generoso; terapeuta; mesías salvador; héroe; conejillo de indias, como él mismo se denomina; y siempre modelo al que seguir. El análisis cuantitativo nos ofrece datos realmente

${ }^{26}$ En otras ocasiones los mensajes se cierran con expresiones de buenos deseos a su auditorio, con reflexiones de corte filosófico sobre la vida, consejos a todos sus seguidores en general o a los enfermos en particular. Otro grupo de vídeos concluye con amenazas o acusaciones a quienes lo persiguen o no le prestan atención; y algunos acaban con un grito de dolor y desesperación, como técnica de dramatización.

${ }^{27}$ PS toma del ámbito de la publicidad el interés por obtener la opinión que de él tienen los seguidores, conocer lo que piensan. Y así lo expone expresamente en uno de sus vídeos: «La verdad que estoy muy contento del llamamiento que hice que me enviarais vídeos diciendo qué era para vosotros Paco Sanz, porque para mí primero me ha llenado de orgullo de saber que lleno de energía y, sobre todo, de esperanza a tanta gente, porque para mí ante todo, y lo digo muchas veces, para mí lo importante es llenar y llegar a la gente de esperanza» (vídeo 32). 
concluyentes en cuanto al grado de ocurrencia de la deíxis mediante el pronombre personal de primera persona singular, yo, que cuenta con 356 apariciones -de 3196 tipos (types)-, ocupando la decimocuarta posición de la lista de palabras que conforman el corpus. El posesivo $m i$ aparece en la posición vigesimosegunda con 230 casos; su plural registra 43 ocurrencias y el pronombre mi, 153 apariciones.

Su egolatría se pone de manifiesto cuando muestra su orgullo por contar con un himno, además de que la asociación de enfermos con síndrome de Cowden lleva su nombre:

No hay nada más bonito que tener un himno de vida, yo ya me siento, lo mismo que me sentía orgulloso cuando la asociación Paco Sanz tenía mi nombre; Un ejemplo a seguir en realidad se va a llamar Un ejemplo a seguir se llama Paco Sanz; y para mí eso..., yo ya no estaré pero siempre quedará para los ancestros, una canción que a la gente le va a dar ganas de vivir, va a ser una historia triste, una historia que llega al corazón, pero una historia que yo quiero que a vosotros os dé alegría y ganas de luchar, y que no hay nada por perdido, que habrá alguna historia de vida (vídeo 10).

No obstante, los vídeos de PS suelen mostrar fluctuaciones más o menos radicales en la presentación de su yo, oscilando entre una pose arrogante del que se presenta como un ejemplo al que seguir, como acabamos de señalar; y la modestia y la humildad de fragmentos donde otorga todo el protagonismo -interesado- a los seguidores que lo apoyan:

Porque yo no me considero ningún protagonista, los verdaderos protagonistas de esta lucha sois vosotros porque sois vosotros con vuestro cariño $\mathrm{y}$, sobre todo, con estos mensajes, con vuestras llamadas, con vuestros whatsapp, sois los que me hacéis que yo tenga esas ganas de vivir y esas ganas de luchar que se me caracteriza (vídeo 32).

Es una manifestación de los dos polos que antes comentamos, una puesta en escena paradójica, contradictoria, que dirige todos sus mensajes.

Ese yoísmo discursivo se camufla en el tú en construcciones aparentemente impersonales que son, en realidad, un fingimiento expresivo, un recurso de atenuación ( «Cuando tú estás pidiendo ayuda, pero tú no pides ayuda para irte de vacaciones, tú no pides ayuda para para pasártelo bien, pides ayuda para vivir, pides ayuda para poder seguir estando porque lo que verdaderamente quieres es luchar», vídeo 41), aunque muchas veces no parece sino una manera de incorporar al oyente, a modo de consejo, en la descripción de una situación compartida (Vigara Tauste 2000): «Primero hay que vivir el presente, el futuro se escribe solo, pero si tú no arreglas tu pasado, tú no puedes vivir tu presente» (vídeo 30). Es lo mismo que ocurre con uno, que viene a mitigar su egocentrismo ( Quiero pedir disculpas 
por el sonido, me grabo con el móvil; uno hace lo que puede», vídeo 18). Se trata de recursos con los que el hablante se distancia del enunciado o generaliza la expresión para atenuar su presencia.

Por otro lado, las autorreferencias y las automenciones surgen continuamente para cumplir distintas funciones:

1. Como un intento de avalar la veracidad de lo que cuenta ( Esta enfermedad, como ya dije en el vídeo anterior, me está comiendo por dentro», vídeo 22);

2. Como fórmula para introducir nuevamente su petición de ayuda o un contenido que se reitera ( «Siempre os lo digo, podéis enviar un mensaje», vídeo 6 // «Como siempre os lo digo y siempre, y nunca perdáis siempre la sonrisa siempre», vídeo 8).

Pero este yo propagandístico, que genera un discurso mediático para conmover por su enfermedad, necesita de los otros, del auditorio que se hace consumidor de sus ideas, de sus mensajes, de su enfermedad y que le proporciona atención y apoyo. Esos receptores, sin hablar, participan en tanto el emisor los instaura como tales (Rivarola 1984: 202). Ese público al que apela continuamente en sus intervenciones y al que se dirige de una manera cercana aparece representado bajo la forma de plural de segunda persona vosotros, y, buscando un trato más cercano, del vocativo cariñoso familia, con 56 apariciones. En los 46 vídeos de nuestro corpus se advierte una evolución empática que va del vocativo todos («Hola a todos») a familia («Hola, familia») en la fórmula de saludo de comienzo de la grabación; además de su significado léxico alusivo al conjunto de personas que comparten sus opiniones -acepción quinta del lema familia en el Diccionario de la lengua española-, esta voz representa una variación expresiva de la función fática que denota el interés de PS por estrechar su acercamiento y aumentar el grado de familiaridad, su complicidad y la confianza con los seguidores; este uso absolutamente intencional denota una relación social de proximidad o de igualdad entre pares que se corresponde con el prototipo de lo coloquial antes comentado (Briz 2010: 126).

No obstante, sus imprecaciones se hacen crítica mordaz y amenaza cuando se dirigen a otra parte de su auditorio: los políticos («Porque es que es tanta la injusticia y es tanto la pena y el dolor que tengo a consecuencia de esta corrupción política que tenemos en este país, porque es inaudito», vídeo 6); o aquellos que lo critican, como cuando se refiere a un señor que lo está acusando de infamias en las redes y al que insulta ( Y qué es lo que pasa: cierra la cuenta, la IP queda, tonto, la IP queda; entonces no hay ningún problema, delitos telemáticos te va a pillar exactamente igual», vídeo 25). 


\subsection{Apelaciones al interlocutor}

\subsubsection{Los imperativos}

En la parte más puramente comercial de sus vídeos, colocada generalmente al final de los mensajes, como avanzamos anteriormente, los imperativos $-y$ con frecuencia los infinitivos con valor de imperativo (como rasgo característico del registro coloquial)-, representan el control directo de la acción propia del discurso de abuso de poder mediante una función directiva pragmática (fuerza de elocución) (van Dijk 2009: 73) con la cual PS trata de imponer a sus seguidores de una manera coercitiva ${ }^{28} \mathrm{y}$, por tanto, impropia del imperativo publicitario actual ${ }^{29}$, la colaboración con su causa; como se aprecia cuando anuncia su libro: «El mejor regalo que podéis hacer esta Navidad, pedírselo a Papá Noel, pedírselo a los Reyes Magos, traernos esperanza» (vídeo 31). En ocasiones se emplea la forma del infinitivo con función de imprecación al final de los vídeos como cierre expeditivo: «Para terminar, solo quiero decir una cosa: ser solidarios, la vida me ha enseñando que no existen ideas políticas, no existen, son personas» (vídeo 28). Cuando critica las estrategias persuasivas del discurso comercial, remite a marcos profundos mediante los cuales está realmente descubriendo su propio proceder en buena parte de sus vídeos: «Pero yo sé que, claro, lo que se está diciendo no siempre voy a estar hablando: "Por favor, compra, compra el libro, por favor, mándame un mensaje”; también quiero dar un mensaje de positivismo, un mensaje de alegría, un mensaje de "sí se puede" (vídeo 16).

Incluso, como ocurre en el mensaje comercial, cuando habla de su libro, PS limita la información que ofrece y dirige al auditorio a la compra:

Es que tampoco quiero desvelar tantas cosas porque el que quiera saber algo de verdad que eche una mano, que eche una mano a esta lucha, que eche una mano; porque no es luchar por mí es luchar por todos; porque esto es una lucha de todos. Luchar contra el cáncer genético. Compren el libro: ahí está todo; que manden un mensaje, que hagan mil cosas. Se puede ayudar hasta con las palabras, que muy bien lo pongo en el libro (vídeo 36).

Para mitigar la orden, atenuar la fuerza asertiva y ocultarla en un ofrecimiento, PS recurre a la fórmula con el verbo poder en presente con la que

28 Actualmente el poder en las sociedades democráticas, como señala van Dijk (2009: 123), es persuasivo y manipulador antes que coercitivo; no obstante, PS con sus imperativos recupera el sentido exhortativo y agresivo del discurso publicitario del compra, usa, prueba, etc.

${ }^{29}$ En la publicidad de las últimas décadas el imperativo se utiliza como invitación, ofrecimiento o incitación sutil y sugerente, ya que se construye sobre bases léxicas de verbos marcados positivamente como disfruta, siente, vive, saborea, etc. (Robles Ávila 2009). 
ninguna de las partes ve amenazada su imagen positiva (Haverkate 1994): «Así que, por favor, podéis entrar en mi web que es <ayudapacosanz.com> repito <ayudapacosanz.com> y ahí podéis echarme una mano, podéis mandarme desde un euro, desde lo que sea» (vídeo 5). Mucho más expeditivo resulta el uso del presente de indicativo con valor imperativo, como en «Cogéis el teléfono y mandáis un SMS...» (vídeo 14).

No obstante, su petición de ayuda se hace desesperada y adquiere un mayor dramatismo a medida que va pasando el tiempo, cuando no satisface sus expectativas: «Por favor, ayudarme, de verdad, no sé ya cómo decirlo, no sé cómo pedir, por favor necesito esa inyección de esperanza, esa inyección de de ganas de luchar» (vídeo 17). O cuando dice: «Tengo que luchar yo mismo, pero claro yo solo con esto no puedo si no me ayudáis y, por favor, os lo pido encarecidamente, encarecidamente, perdón, ayuda...» (vídeo 40). Además, en los últimos vídeos, cuando parece que se estrecha el cerco y está a punto de descubrirse su estafa, las imprecaciones de colaboración a los seguidores adquieren mayor intensidad; de hecho, estas son las palabras con las que cierra su último vídeo: «Por favor, ayudadme y no os olvidéis de mí [...]. Por favor, echarme una mano» (vídeo 46). No obstante, en todos los casos PS emplea la fórmula de cortesía por favor con la que trata de mitigar su fuerza impositiva.

Por otra parte, utiliza los imperativos no como orden sino como recomendación cuando, en su faceta de consejero, se dirige a su auditorio alejándose del fin comercial e inclinándose a lo propagandístico de un líder que anima a sus seguidores a compartir sus propuestas de vida y de actuación:

\footnotetext{
Búscate una alegría, búscate un hobby, búscate algo por lo que luchar, agárrate fuerte a tu familia, agárrate fuerte a tus amigos, que eso es jamás te dejarán de lado. Y vuelvo a ser otra vez repetitivo: agárrate a la vida y no te dejes vencer; un consejo que os doy: agárrate al amor, el amor a las personas, el amor a la familia, el amor por los animales, el amor por la vida, el amor por ti, empiézate a querer, si no te has empezado a querer. Di te quiero (vídeo 24).
}

Entre las obsesiones de PS está la de mantener viva su historia, no caer en el olvido, algo que sin tapujos repite a lo largo del tiempo ( $Q$ Que tengo que hacer un cambio radical, pienso yo, y la forma de ver las cosas, sí, para que mi noticia nunca muera, eso es lo que estoy intentando», vídeo 45); por ello, resulta reiterativo el empleo del verbo acordarse en imperativo -o en infinitivo con valor imperativo- («Acordaos que esta lucha sigue», vídeo 27 // «Acordaros, Paco Sanz, una vida de los sueños, una vida de lucha, estaréis regalando, sobre todo, esperanza y ganas de vivir», vídeo 31 // «Acordaros de este humilde luchador por la vida, que si en un momento 
en estas fiestas sonreís, yo me estaré acordando de vosotros porque vuestra sonrisa», vídeo 33). Este verbo también se emplea como amenaza para mover a la ayuda ("Acordaros que el cáncer genético es, está ahí y tenemos que luchar y juntos vamos a poder contra ello porque la unión hace la fuerza», vídeo 7).

Como se aprecia, el imperativo -o el infinitivo con valor exhortativo- es la forma más representativa de las secciones donde prevalece lo publicitario: aquellas que suelen cerrar la pieza audiovisual y donde PS, sin rodeos, pide la ayuda y ofrece las diversas formas de colaboración. Unos imperativos -o infinitivos- que, como en el texto publicitario (Robles Ávila 2005c: 242-244), suelen ir en la apódosis de construcciones condicionales para ofrecer a los seguidores diversas alternativas de donación:

De verdad, por favor, acordaros siempre de lo que os digo: si queréis echar una mano a la lucha contra el cáncer, si quieres echar una mano aquí porque nunca sabes cuándo puede llamar a nuestra puerta, y lo digo siempre, por favor, entrar en $<w w w$.ayudapacosanz.com $>$ o solamente poniendo $<$ ayudapacosanz.com>. Y, si no os apetece entrar en la web y queréis ir mandar un simple mensaje de texto, mandar paco al 25600 el precio será 145 céntimos; por favor paco, al 25600 o entrar en <ayudapacosanz.com>. Muchísimas gracias y felices sonrisas (vídeo 7).

El imperativo también adquiere un papel relevante cuando lanza acusaciones y amenazas, como las que profiere a la que era por entonces vicepresidenta de la Generalitat Valenciana, Mónica Oltra, a quien ataca verbalmente por no cumplir con su compromiso de otorgar las ayudas prometidas: «Y que no quiero que se me olvide mandar un mensaje a D. ${ }^{\text {a }}$ Mónica Oltra: "Por favor, deje de faltar a la verdad" (vídeo 41). Lo mismo sucede en las imprecaciones al enemigo que trata de descubrir la estafa que está llevando a cabo y al que apela ahora con el despectivo machote: «Te lo has ganado, machote, ya tienes tu denuncia: injurias y calumnias [...] si tienes tantas ganas y tanto amor que me tienes, vente aquí a Valencia» (vídeo 12).

El imperativo lexicalizado mirad -y en ocasiones mira o el infinitivo mirar- es el más empleado como fórmula fatico-apelativa (22 apariciones). Como ocurre con otros verbos de percepción (oye, ¿sabes?, etc.), se trata de voces que han perdido su significado original y se convierten en «reguladores fáticos, llamadas de atención o refuerzos argumentativos» (Briz 1998: 99): «Hola, ¿qué tal? Pues, mira, ya por fin ya nos vamos para casa (vídeo 39) // Mirad, yo llevo quimio diaria pero bueno intento que no se note» (vídeo 3 ).

También el imperativo toma tintes solidarios en la forma nosotros, que incluye al hablante como parte de la pluralidad y es propio del discurso publicitario de la llamada publicidad de compromiso, así como del habla colo- 
quial: «Por favor, hagamos que estas navidades se llene de vida. En mi web podéis cómpralo en <ayudapacosanz.com>» (vídeo 31). PS, dependiendo de sus intereses, puede recurrir a la pluralidad como estrategia persuasiva para crear sentimiento de grupo y estrechar los lazos con el auditorio.

\subsubsection{La interacción fingida: las preguntas autorrespondidas y las preguntas retóricas}

El diálogo imaginario con sus seguidores que recrea PS aparece salpicado con fórmulas de pregunta-respuesta: «¿Qué es el síndrome de Cowden? el síndrome de Cowden es un raro cáncer genético que tenemos muy poquitas personas en el mundo» (vídeo 1) // "¿Cuál es mi ilusión ahora? Esta gala» (vídeo 1) // "¿Qué me ha dado EE.UU.? Vivir y alegría» (vídeo 28).

Además, en su deseo fingido de mostrar transparencia y sinceridad en sus mensajes recurre con mucha frecuencia a interrogativas introducidas con por qué a las que ofrece respuestas justificativas que explican la razón de lo que dice y hace: «Este vídeo es para darle las gracias, las gracias. ¿por qué? por tener 20 mil seguidores en Twitter» (vídeo 14) // «Hoy estoy... es esta enfermedad, tiene subidas y bajadas sobre todo psicológicas, ¿por qué? Porque, claro, estamos hablando de que esto es un cáncer genético, esto afecta a todo todo el cuerpo» (vídeo 15).

En ocasiones las interrogativas se encadenan como en «Lo que pido es vivir, [...] poder tener una vida normal; ¿qué es lo que ocurre? Que esa normalidad de mi vida vale dinero, vale mucho dinero. ¿Por qué? Porque tengo una enfermedad rara» (vídeo 15). La causal adquiere un mayor dramatismo cuando le siguen respuestas que se muestran como interrogativas totales: «¿Por qué es?, ¿porque lleve cinco años luchando por sobrevivir?, ¿porque le haya vencido a la muerte ya unas cuantas veces ya no tengo más derecho a la ayuda, ya no tengo más derecho a la vida? Pues yo creo que es una parte bastante cruel tratada por los medios de comunicación y por algunas personas» (vídeo 20). Y en otros casos, se encadenan en enumeraciones de gran eficacia expresiva: «¿Por qué? ¿porque la enfermedad no sale en la foto; porque, porque la enfermedad no tiene votos, porque nosotros no somos personas, somos votos?» (vídeo 22).

Otras veces él mismo lanza las preguntas como recurso para crear una curiosidad que satisface inmediatamente: «¿Sabéis cómo me siento? Vivo» (vídeo 3). La estrategia apelativa clásica de llamar la atención del auditorio lanzándole preguntas construidas de tal manera que orientan el sentido de la respuesta queda patente en series como las que siguen, donde PS avanza en esa intención manipuladora de la voluntad de sus oyentes aportando pruebas que demandan una respuesta predeterminada y, en último lugar, cierra con una interrogativa aglutinadora que supone la confirmación final: 
¿Creéis que si todo lo que se ha dicho sobre el libro hubiera sido verdad el libro todavía seguiría? ¿la gente hubiera apostado por el libro? ¿se hubiera hecho una presentación en la librería Leo de Valencia, una de las librerías más importantes que hay aquí en Valencia?; ¿vosotros creéis que es así? (vídeo 18).

En realidad, el enunciado interrogativo rompe su prototipicidad y no pregunta, sino que asevera (Garrido Medina 1999: 3905), como sucede cuando, a medida que su caso va levantando sospechas y sus expectativas de lucro no se satisfacen, surgen interrogativas retóricas de gran dramatismo: «Pero ¿dónde están esos grandes amigos, esos grandes apoyos que siempre estaban ahí y en cualquier momento?» (vídeo 34) // “¿Qué va a ser de nosotros? Yo no he pedido estar enfermo, yo no he pedido estar así» (vídeo 41).

\subsubsection{Los vocativos: imprecaciones catárticas al auditorio}

Cumpliendo una función fática, PS recurre continuamente a estos elementos cargados de máxima urgencia expresiva para enfocar aspectos que considera relevantes, enfatizar el papel del referido, es decir, lo imprecado: actos ilocutivos, función apelativa pura (Labrador Gutiérrez 2004: 148) y así mantener el contacto con el interlocutor; de hecho, y como se apuntó más arriba, arranca sus intervenciones con una frase ritualizada que incluye la fórmula pragmática apreciativa familia, con la que exhibe una cercanía con su grupo de seguidores, propia de la interacción coloquial, para dirigirse a sus iguales. El mismo apelativo se emplea para cerrar muchos de sus vídeos: «Os quiero, familia». Más extraña resulta su aparición en medio del vídeo: «Familia, no quiero enrollarme más, es que estoy bastante indignado...» (vídeo 18).

El mismo tono cercano hacia el interlocutor se manifiesta en el uso de amigo («Muchas cosas, muchas cosas, amigo mío», vídeo 45), que remite a un marco profundo que dirige al oyente a valores de camaradería y empatía, a la pertenencia a un mismo grupo. Unos amigos que se concretan en individuos particulares a los que PS se dirige para agradecerles su apoyo, esas buenas personas, como él mismo denomina reiteradamente, que le ayudan y que gracias a ellas se mantiene vivo - «Llevo cinco años, llevo cinco años luchando contra el cáncer genético y siempre le ha ganado la partida o con la ayuda de todos vosotros, con la ayuda de las buenas personas, siempre he podido» (vídeo 13) // «Gracias, Lucía Carmona, un beso muy grande» (vídeo 20) // «Muchas gracias, Nano, de verdad» (video 19)-, aunque lo más frecuente es la automención mediante la reproducción de las palabras de otros en las que surgen apelaciones a su propia persona y donde, sin 
ningún pudor, replica elogios y halagos que supuestamente le dispensan sus seguidores: «Paco, eres mi ejemplo, eres mi héroe» (vídeo 10)// «Gracias a lo que tú has hecho, Paco, que has conseguido salvar a muchas personas» (vídeo 5) // "Muchas veces me dicen: "No, Paco, eres un luchador"» (vídeo 8) // «Oye, Paco, gracias a ti, he conseguido muchas cosas» (vídeo 23).

Esas imprecaciones, cuando se dirigen a sus supuestos enemigos o a los políticos se hacen agresivas, irónicas y despectivas, según el momento, y se suelen acompañar de interrogativas del tipo $\dot{\zeta}$ sabes?, ¿no?, ¿verdad?, enfocadores de la alteridad (Martín Zorraquino y Portolés 1999) que desarrollan un carácter desafiante (Heritage 2002: 1427) y que surgen a modo de muletillas, elementos de apoyo y engarzadores del discurso (Fuentes Rodríguez 1995): [refiriéndose al que denonima ese señor, que responde a una persona que empieza a difundir en las redes que PS es un estafador] «Es que tú eres tan guapo, bonito, tiene que estar guapo ¿sabes?» (vídeo 29) // «Te lo has ganado, machote, ya tienes tu denuncia» (vídeo 12).

O esta otra interrogativa que dirige a Mónica Oltra: «Un mensaje a doña Mónica Oltra: “¿Usted se cree que con un solo mensaje de twitter para salvar una vida? Usted me prometió que me iba a ayudar, ¿qué es?, ¿una política más?”» (vídeo 41).

\subsubsection{Eslóganes y otras frases memorables}

A pesar de ser un discurso oral escasamente planificado, como se detecta a través de los rasgos que venimos señalando, PS hace uso de una serie de piezas discursivas -eslóganes, titulares, entradillas, etc.- que tiene bien aprendidas por su finalidad perlocutiva y con las que intensifica la expresividad de sus mensajes. La muestra más representativa es, como se señaló anteriormente, las entradillas que dan inicio a la mayoría de sus vídeos y que replica con leves modificaciones, generalmente ajustadas al momento del día o de la semana; estas se convierten en señas de identidad introductorias de sus mensajes ${ }^{30}$ y preparan al auditorio para su dosis publipropagandística: «¿Qué tal? Buenos días, familia, ¿cómo estamos? Espero que bien y que la sonrisa os haya acompañado durante todo el fin de semana» (vídeo 18).

Como en los anuncios comerciales, las ideas-fuerza sobre las que arma sus intervenciones se expresan mediante enunciados apelativos que, acomodándose a la temática del vídeo, aparecen en sus mensajes continuamente

\footnotetext{
${ }^{30}$ Esta fórmula introductoria de saludo aparece tan ritualizada que la repite a una velocidad de locución tal que a veces se hace incomprensible, como ocurre en el vídeo que titula Help.
} 
y denotan un carácter estratégico asociado a una finalidad perlocutiva (Fernández Gómez 2005): Regala vida estas Navidades (vídeo 31). Su funcionalidad es la propia del eslogan que se fija en la mente del seguidor portando un contenido que a nuestro alocutor le interesa que sea memorizado y replicado, y que, para facilitar el recuerdo, hace uso de diferentes técnicas, como el empleo de estructuras paralelísticas: Ganas de vivir, ganas de luchar (vídeo 31). Se trata de expresiones lingüísticas significativas, perdurables y muy eficientes (Garrido Lora 2000) que soportan una potente carga connotativa y manipuladora; gritos de guerra (Sánchez Guzmán 1995: 82) que remiten a marcos profundos y ocultan el abuso de poder y el dominio del estafador.

Además, sus mensajes suelen acompañarse de cuñas musicales de cierre que corresponden al estribillo de la canción que compuso para él el conocido rapero Driak; todo ello al más puro estilo comercial ${ }^{31}$ : «Lucha por su vida [...] un ejemplo a seguir». Con estos jingles, el eslogan cantado es un recordatorio (Figueroa 1999; Taube 2001; Fernández Gómez 2005) y permite insistir en determinadas ideas que, sin música, podrían irritar al oyente (Bassat 2001: 157).

Junto a los eslóganes publicitarios, PS emplea toda una serie de frases sentenciosas que plantea como verdades absolutas, aforismos y lemas que se convierten en argumentos propagandísticos de verdad absoluta que activan marcos profundos asociados a la empatía y la solidaridad: «Querer es poder» (vídeo 37), «Sonreírle a la vida que la vida te lo va a devolver» (vídeo 31), «En el término medio está la virtud» (vídeo 44) u «Hoy por mí, mañana por ti» (vídeo 46).

Incluso recurre a citas célebres seleccionadas estratégicamente por su eficacia expresiva como la de Vegecio -erróneamente atribuida por PS a Julio César-, Si vis pacem, para bellum (vídeo 21), como justificación para atacar a los que lo critican y no creen en él. O la que reproduce de forma inexacta de la célebre de M. Luther King: «Si esta lucha merece a una persona, la esperanza habrá merecido la pena» (vídeo 23) -en lugar de «Si ayudo a una sola persona a tener esperanza, no habré vivido en vano»-, que de manera heroica se aplica por su mesianismo autoadquirido. También la cita de Calderón de la Barca le sirve como cierre a una de sus reflexiones sobre su anhelo de curarse: «Porque me queda mucho por hacer, yo quería haber luchado más antes de haberme ido, pero bueno como muchas veces se piensa toda la vida es sueño y los sueños, sueños son» (vídeo 27).

31 El estribillo dice: «Él es un buen hombre, con un gran corazón, a pesar de los problemas jamás pierde la ilusión. Lucha por su vida sin dejar de sonreír; su nombre es Paco Sanz, un ejemplo a seguir». 


\subsection{La intensificación expresiva}

Además de estos rasgos apelativos y propiciadores de un diálogo simulado con sus seguidores, desde el punto de vista de la funcionalidad comunicativa, destacan los recursos de intensificación propios de la comunicación oral coloquial con los que PS trata de impresionar a su auditorio; muchos de ellos resultan coincidentes con los del lenguaje publicitario y propagandístico de autopromoción. La intensificación, siguiendo a Briz (2003: 19), se ha de entender como una categoría pragmática donde determinadas formas se asocian a actividades estratégicas, afectando tanto al decir como a lo dicho, al valor intencional y a la fuerza ilocutiva. Con la categoría de los intensificadores se realza al hablante, es una estrategia comunicativa de producción, de codificación mediante la cual se muestra la intención de este: su propósito de influir en el oyente ${ }^{32}$.

Por lo que se refiere a las clases de palabras, destaca la adjetivación valorativa, subjetiva e hiperbólica, al más puro estilo comercial (Robles Ávila 2004; Romero Gualda 2006), mediante adjetivos como horrible («Quiero mandaros una fuerza horrible», vídeo 6), fenomenal («Para que los que no podáis venir, por lo menos podáis ver ese fenomenal evento que vamos a hacer», vídeo 19), único («Soy la única persona en el mundo que está tomando esta medicación durante tanto tiempo», vídeo 6), gran/grande («Vamos a tener grandes sorpresas, repito grandes sorpresas», vídeo 19) o nuevo, el adjetivo publicitario por excelencia (Robles Ávila 2004: 18-19) («Un nuevo tratamiento», vídeo 1 ; «Un nuevo proyecto», vídeo 46; «Nueva etapa», vídeo 46; etc.). Precisamente, el gusto por la novedad propio del discurso comercial se manifiesta en la intención de PS de anunciar al comienzo de cada vídeo que va a ser diferente y original, y así crear el interés, la curiosidad y aumentar las expectativas del seguidor sobre los mensajes: «Yo me gustaría lanzar un mensaje hoy diferente» (vídeo 16) // «Hoy quiero hacer un vídeo diferente» (vídeo 24) // «Buenos días, hoy me gustaría hacer algo diferente» (vídeo 3 ).

Los cuantificadores también son muy recurrentes, en especial el universal ponderativo por excelencia del lenguaje publicitario todo (Robles Ávila 2004: 13-14) -y sus variantes de género y número- («Invito a toda la gente de Valencia, a todas las gentes de alrededores, a toda la gente que quiera venir, librería Leo de Valencia, sábado 7 de mayo a las 7 y media de la tarde», vídeo 19), así como el cuantificador no universal evaluativo mucho

\footnotetext{
${ }^{32}$ Sobre la intensificación en el español coloquial, véase Albelda (2005 y 2007), quien realiza un profundo estudio sobre este fenómeno superando los aspectos semánticos para considerarlo desde una perspectiva comunicativa, como una categoría pragmática empleada por los hablantes mediante una determinada estrategia lingüística.
} 
(Sánchez López 1999: 1046) -y sus variantes de género y número- («Mucho trabajo, mucho sufrimiento, pero sobre todo mucha esperanza es lo que va a haber este día, el día de, por fin, esta presentación», vídeo 20).

En su hablar particular se aprecia una tendencia al empleo de epítetos con los que se abunda en una información conocida que, no obstante, se quiere destacar para aumentar el dramatismo: «mala quimioterapia» (vídeo 34), «ese maldito cáncer genético» (vídeo 8) o «terrible enfermedad» (vídeo 1).

Igualmente abundan los adjetivos en grado superlativo, en especial los absolutos: "No tenías dinero no puedes hacer nada, lo poquito que tenía era para comer y era la verdad que fue durísimo» (vídeo 1) // «Soy la primera persona en el mundo que tiene un quimioterápico tantísimo tiempo» (vídeo 5); unos superlativos que se acumulan en el discurso y aumentan el grado de expresividad: "Necesito la ayuda de las buenas personas, necesito la ayuda de muchísima gente porque yo solo no puedo luchar, porque esta lucha es durísima, durísima» (vídeo 13).

Del grupo de adverbios destaca la presencia del intensificador comparativo más, con 108 apariciones, que manifiesta la fuerza expresiva del discurso oral de PS ante sus seguidores, su énfasis y tendencia a lo exagerado e incluso hiperbólico: «Soy una persona que ama la vida, ama la vida más que nada» (vídeo 30) // «Una reflexión desde lo más profundo de mi corazón» (vídeo 30) // «Y sobre todo, más que otra cosa, tengo miedo» (vídeo 34); y es elemento indispensable para transmitir desconsuelo y desesperación: «Yo no quiero dar pena, yo solo pido ayuda para vivir, ayuda para seguir porque no puedo más, os lo digo de verdad, no puedo más, no puedo más» (vídeo 5). Pero PS utiliza este adverbio expresivo y valorativo para solicitar a sus interlocutores que aumenten su ayuda; incluso le sirve para cuestionarles el grado de implicación en su causa, recriminándoles de manera subliminal que no lo apoyan suficientemente: «Acordaros 673711371 y podéis llamar siempre, yo estoy dispuesto para daros alegría y sobre todo esperanza y, sobre todo, que siempre se puede hacer más» (vídeo 21).

Además es, después de más, el adverbio con mayor grado de ocurrencia en los vídeos, con 36 apariciones. Su valor de adición supone en este discurso una intensificación de la línea argumentativa que PS va exponiendo («Este libro, además de darme la vida, me sacó del túnel oscuro que estaba yo metido», vídeo 16); y aumenta cuando se acumulan en un mismo enunciado ( «Tengo además de las continuas bajadas de defensas, me lleno entero de llagas; tengo, además, problemas en cuestión de grandes infecciones», vídeo 1). En este discurso oral no planificado se convierte en una muletilla, un tic personal que emplea continuamente porque conoce bien de su eficacia expresiva: «Yo le gano en el terreno de la vida y en el plano deportivo que tiene un poquito el levantarme por las mañanas y decir 
además de ir al hospital, además de ir mis cosas médicas, además tengo una faena que es el correr el el por lo menos el hacer un poquito de deporte» (vídeo 9).

Otro recurso de intensificación -y también de cuantificación- propio de la comunicación comercial oral no planificada y de la propaganda es la repetición de palabras, sintagmas u oraciones que crean un discurso ecoico propio del registro coloquial. Con esta técnica PS evidencia la eficacia de fijar en la mente de su auditorio ciertos datos, ciertas palabras clave que se acoplen a sus marcos de pensamiento, a sus paradigmas o actos previos de categorización (Sefchovich 2014: 138) y que le permitan entender e interpretarlos en el sentido previsto, acomodado a ese esquema o molde interpretativo que le da sentido: «Los enfermos de cáncer genético tienen mucha depresión, como digo yo, subidas y bajadas, tenemos muchísimas subidas y bajadas» (vídeo 3) // «Y ha sido muy duro el camino, ha sido muy duro» (vídeo 1). Nótese que las repeticiones son de segmentos que están marcados semánticamente, dirigen a unos marcos cognitivos asociados al dolor, lo que en la reiteración adquieren una mayor tensión y una intencionalidad perlocutiva. Además, al ser esta estrategia un rasgo coloquializador, apela al interlocutor, crea complicidad y empatía con él y le acerca el mensaje de una manera más natural: «En España no existe ningún fármaco, ningún tratamiento, nada de nada, de nada» (vídeo 1).

Estas repeticiones son exactas o presentan variaciones -reformulaciones- con las que este alocutor trata de salvar potenciales obstáculos en la comunicación, ante su sospecha de que la información aportada pudiera ser insuficiente (Gülich y Kotschi 1995) y precise de un énfasis mayor; para ello, suele recurrir al encadenamiento, que intensifica la tensión: «Lo estoy pasando muy mal y cada día lo estoy pasando peor, y cada día un poquito peor» (vídeo 5).

Igualmente, las estructuras paralelísticas implican la repetición de patrones con lo que se refuerza el mensaje, ya sean aumentando la fuerza comunicativa ( Basta de torpedeos, basta de de intentar hacerme daño y basta de todo», vídeo 12), o disminuyéndola («Dentro de esa sonrisa dentro de esa siempre está sonriendo, también puede haber un drama, puede haber un problema o puede haber ganas de llorar», vídeo 12). Consciente de la eficacia de los paralelismos, evita incluso la conjunción copulativa entre los dos segmentos y así impide que se rompa el equilibrio de ambos: «Yo os daría cultura, vosotros me daréis vida» (vídeo 46).

PS recurre al empleo de repeticiones como técnica de énfasis de su mensaje y para hacerlo memorable, de ahí que con frecuencia utilice la fórmula repito con la que apela al lector y dirige su atención sobre determinada información: «Vamos a tener grandes sorpresas, repito grandes sorpresas y, sobre todo, vamos a reír» (vídeo 19); o como técnica de dramatización 
para impresionar al auditorio y ganarse su benevolencia: «Yo ahora no lo tengo muy acusado por la quimioterapia que tomo diaria, repito, quimioterapia que tomo diaria» (vídeo 29) // «Yo soy un conejillo de indias y han experimentado conmigo muchísimas veces y repito un conejillo de indias» (vídeo 5). La fórmula repito es más comúnmente empleada cuando quiere insistir en ciertos datos de su interés, como los relacionados con el lugar, la fecha y la hora de presentación de su libro (17 de las 25 ocurrencias): «Repito 7 de mayo 7 y media de la tarde librería Leo presentación Paco Sanz, una vida de los sueños, una vida de lucha» (vídeo 19). Y la conciencia del efecto de este recurso se hace más apreciable cuando aparece en la parte final de sus mensajes, cuando solicita la ayuda mediante el envío de un mensaje de texto o invita a entrar en su web al más puro estilo comercial: "Cogéis el teléfono y mandáis un SMS con la palabra Paco al 25600, repito Paco al 25600 a 1,45 euros» (vídeo 14) // «Podéis entrar en <ayuda pacosanz.com>, repito en <ayudapacosanz.com>» (vídeo 12).

Toda esta retórica de la repetición es verbalizada por el propio PS cuando reconoce abiertamente su tendencia y expone su propósito de evitarla: «Solamente no quiero volver a ser repetitivo con lo mismo, de verdad» (vídeo 25) // «Para terminar, porque tampoco quiero ser como siempre repetitivo, ni quiero ser pesado siempre con lo mismo» (vídeo 17); aunque, si el mensaje es un consejo o una recomendación a sus seguidores, se jacta de ser reiterativo: «Y vuelvo a ser otra vez repetitivo: agárrate a la vida y no te dejes vencer» (vídeo 24).

En cualquier caso, es en el empleo de estas técnicas reiterativas, ya sean repeticiones, patrones paralelísticos o elementos léxicos que denotan esta acción, donde se percibe con más nitidez el carácter publicitario de los mensajes. Igualmente son técnicas propias del discurso propagandístico oral espontáneo mediante las cuales el orador organiza su discurso, mantiene el hilo expositivo y viene a cubrir potenciales lapsus de memoria que pudieran interrumpir su alocución. De todas estas propiedades es buen conocedor PS, de ahí que sus discursos se sustenten en estos recursos nemotécnicos.

Por otra parte, la intensificación se consigue mediante procedimientos retóricos al servicio de la función expresiva y emotiva de la lengua, en el ámbito de la afectividad y de las intenciones del hablante. PS hace uso de estos artificios por el lucimiento en la exposición de sus ideas, para impresionar a sus seguidores. De las figuras del habla ${ }^{33}$ con carácter intensificador destacan las hipérboles, las metáforas, las personificaciones, las comparaciones, así como las paradojas.

33 Payrató (1999 [1988]: 121) las denomina de este modo al considerar que el registro coloquial se aproxima a la variedad literaria en tanto ambos suelen coincidir en el empleo de los mismos medios expresivos y estéticos. 
Con las hipérboles se crea ese discurso exagerado con el que impresionar al auditorio. La frase hiperbólica más frecuentemente empleada es Soy la única persona en el mundo, con 5 apariciones; donde se refuerza su egolatría y su centralidad absolutas. Igualmente, cuando se refiere a su libro, no tiene reparo en expresar abiertamente: «Este libro que es una obra de arte» (vídeo 12). También la hipérbole se convierte en el recurso idóneo para referirse a su enfermedad, a los síntomas y a su evolución: «Yo sé que tengo todo el la parte interior desde desde las cuerdas vocales hasta el toda la parte del intestino grueso llena de llagas en este momento» (vídeo 26); y la repetición se suma a la intensificación retórica de la hipérbole: «La garganta la tengo toda llena de llagas, toda la parte de la boca, la tengo toda llena de llagas, todo el aparato digestivo» (vídeo 26). También exagera el tratamiento y su posología: «Los ojos se están secando y gasto una caja de gotas al día» (vídeo 1). Muchas de las hipérboles aumentan el dramatismo de lo enunciado: (refiriéndose al libro) «Es la última llama que me queda para poder seguir viviendo» (vídeo 13).

Pero la intensificación también favorece la aparición de metáforas (Portero 1997; Fernández y Albelda 2002) con las que aumenta la carga expresiva de los lexemas afectados. Las preferidas por PS son las que tienen que ver con ponerse la sonrisa para simbolizar la alegría de vivir, la superación de las dificultades ( Yo me levanto por la mañana me pongo mi sonrisa y a vivir», vídeo 1); y las que se refieren al cáncer, renombrado como el bicho ( «Se ha despertado el bicho, se ha despertado, se ha despertado con fuerza», vídeo 34). Se observa una tendencia al empleo de metáforas militares de la jerga médica (Sontag 2003: 134) que han pasado al habla coloquial y que PS recoge continuamente, como la lucha contra la enfermedad (166 apariciones), la guerra (4 apariciones) o la batalla ( 5 apariciones). También emplea metáforas para crear una secuencia de carácter alegórico, como en «Todos tenemos una parte de niño, que es la más bonita, una parte de adulto y una parte de padre; pensemos que la cabeza es el padre, el corazón es el niño y todos tenemos una una parte de protección con las personas que no que nos rodean, que es la parte de madre, eso tiene que estar siempre más o menos es como un quesito» (vídeo 28). La grandilocuencia encuentra en la construcción de metáforas una eficaz fórmula de expresión: «Fue ese ensayo clínico, fue ese ese colegio de vida» (vídeo 36). Las metáforas también contribuyen a aumentar la tensión dramática, como la que identifica la salud con la gasolina: «Lo estoy pasando muy mal y cada día lo estoy pasando peor, y cada día un poquito peor; la gasolina se me está acabando» (vídeo 5).

Las personificaciones son, igualmente, recursos al servicio de la intensificación de los mensajes: «Hacemos que el dolor sea como un amigo, como una parte de la vida» (vídeo 24). Y refuerzan la tensión: «Felicidad, 
¿dónde estás?» (vídeo 42) // «Una chica, hace poco que me conoció, que tiene una enfermedad muy grave, que convive, como yo, con la muerte» (vídeo 36).

No obstante, son las paradojas los recursos que mejor simbolizan los vaivenes de PS tanto en el contenido de lo que dice como en las fórmulas expresivas que emplea: «La palabra cáncer es una palabra maldita pero tampoco es una palabra que hay que decir muerte, puede ser, pero tampoco alegría pero puede ser esperanza y ganas de vivir» (vídeo 5) // «Un recuerdo que para mí doloroso por lo mal que lo pasé, pero sobre todo alegre» (vídeo 36). Destacan, no obstante, las más radicales: «Sufrir con alegría» (vídeo 17), «Este libro es todo y es nada, es vida y es muerte» (vídeo 31). La relevancia que adquiere la paradoja en el decir de PS es un leitmotiv que se refleja a lo largo de todas sus exposiciones públicas en YouTube: es este mecanismo el que articula sus mensajes y se materializa en el tic personal de carácter coloquial que repite constantemente como partícula lexicalizada, comodín expresivo, pero, bueno..., con el que transmite una afectada resignación -también fingida- que le sirve para empoderarse, para ejercer su dominación sobre los seguidores que, empáticos y compasivos, se someten a sus palabras y actúan en su ayuda: "Y eso lo que da miedo: que un día estés perfecto y al día siguiente ya no te levantas, porque puede contigo. Pero, bueno, es así, la vida» (vídeo 37) // «Hay que cruzar el charco para volver volver a enchufarme y esa luz es cara. Pero, bueno, vamos a intentar entre todos a ver si lo conseguimos y mientras hay vida hay esperanza; vamos a luchar» (vídeo 16).

El decir de PS se presenta, pues, con continuas contradicciones que son, en parte, producto de la falta de planificación de un discurso oral espontáneo que pivota sobre una serie de ideas en torno a las que se construye:

Os quiero desear una una muy bonita entrada de año, que el año que viene sea siempre un poquito mejor que este, para mí mucho mejor. (hombre, espero, porque llevo un año...) que sea muchísimo mejor solamente un poquito y nada solamente eso que seáis muy felices y hasta la el año que viene (vídeo 35 ).

\section{Conclusiones}

Aristóteles en su Retórica afirmaba que «las pruebas por persuasión, las que pueden obtenerse mediante el discurso, son de tres especies: unas residen en el talante del que habla (êthos), otras, en predisponer al oyente de alguna manera (páthos) y, las últimas, en el discurso mismo (lógos), merced a lo que este muestra o parece demostrar» (1356a1-4); y añade que el orador también ha de atender a los efectos del discurso, en cómo ha de 
presentarse uno mismo, porque es muy importante para la persuasión «el modo como se presente el orador respecto de los oyentes [...] para conducirlos al estado emocional adecuado» (1377b22-29). En sus mensajes de vídeo PS atiende a los tres componentes de los que habla Aristóteles: a él mismo, a su auditorio y al mensaje, así como a los efectos en los receptores, con el objetivo, no solo persuasivo sino también manipulador, de recaudar fondos para curar su enfermedad.

Como hemos venido constatando, para urdir su plan el estafador se vale de la naturalidad, la proximidad y la espontaneidad del habla coloquial; y de un uso del lenguaje y una arquitectura discursiva con una finalidad publipropagandística, donde su yo preeminente, que se mueve entre la arrogancia y la modestia, la dominación y la humildad, abusa de la buena voluntad de sus receptores. La selección léxica que remite intencionalmente a marcos cognitivos de significados y connotaciones persuasivos y manipuladores de la voluntad de su auditorio, la tendencia al empleo de determinadas clases de palabras y expresiones perniciosas -especialmente los imperativos exhortativos y coercitivos-, las fórmulas apelativas dirigidas al oyente, los eslóganes de corte publicitario, los recursos de intensificación o el empleo de figuras retóricas, entre otros mecanismos, ponen de manifiesto que estamos ante un discurso de abuso de poder sobre un auditorio manejado estratégicamente por la palabra. PS representa fielmente lo que señalaba van Dijk: «Quienes controlan el discurso pueden controlar indirectamente las mentes de la gente. Y puesto que las acciones de las personas están controladas por sus mentes [...], el control mental también implica el control indirecto de la acción» (van Dijk 2009: 31). En este escenario comunicativo los seguidores, los que podemos denominar sanos, que deberían representar el grupo de poder frente al protagonista enfermo, cambian los papeles y el dominado se convierte en dominador, en poderoso que encuentra en su enfermedad un aval que lo empodera sometiendo con su discurso publipropagandístico a un público que, compasivo, movido por las emociones del estafador, asiente y colabora. 


\section{BIBLIOGRAFÍA}

ADAM, Jean Michel (1991): «Une typologie d'inspiration bakhtinienne: penser l'hétérogéneité textualle», ELA 83, 7-17.

- y Marc Bonhomme (2000): La argumentación publicitaria. Retórica del elogio y de la persuasión, Madrid: Cátedra.

AlbeldA, Marta (2005): La intensificación en el español coloquial, Valencia: Universitat de València. <http://www.tesisenxarxa.net/TESIS_UV/AVAILABLE/TDX-0701 105-125232//albelda.pdf $>$.

- (2007): La intensificación como categoría pragmática: revisión y propuesta, Frankfurt am Main: Peter Lang.

Álvarez Villa, Ángels, Begoña Echevarría Llombart, Carolina Figueras SolaniLlo, Anunciación Ramírez Queralt y Sebastián SÁnchez Castillo (2014): Las enfermedades raras en los medios, Madrid: Observatorio de Enfermedades Raras, OBSER.

ARISTÓTeles (1990): Retórica, trad. Quintín Racionero, Madrid: Gredos.

BASSAT, Luis (2001): El libro rojo de la publicidad, Madrid: Plaza y Janés.

Bañón HeRnández, Antonio (2007): «Las enfermedades raras y su representación discursiva: propuesta para un análisis crítico», Discurso \& Sociedad 1/2, 188-229.

- (2013): «Salud y discurso. A modo de introducción», Discurso \& Sociedad 7/1, $1-25$.

- y Josep Solves Almela (2015): «El debate sobre las enfermedades poco frecuentes: una mirada a través de los medios de comunicación», Métode 88, $62-67$.

BRIz Gómez, Antonio (1996): El español coloquial. Situación y uso, Madrid: Arco/ Libros.

- (1998): El español coloquial en la conversación. Esbozo de una pragmagramática, Barcelona: Ariel.

- (2003): «La estrategia atenuadora en la conversación cotidiana española». En Diana Bravo (ed.), Actas del Primer Coloquio Edice. La perspectiva no etnocentrista de la cortesía: identidad sociocultural de las comunidades hispanohablantes, Universidad de Estocolmo, 17-46.

- (2010): «Lo coloquial y lo formal, el eje de la variedad lingüística». En Rosa M. ${ }^{a}$ Castañez Martín y Vicente Lagüéns (coords.), De moneda nunca usada: Estudios dedicados a José M. ${ }^{a}$ Enguita Utrilla, Zaragoza: Instituto Fernando el Católico, 125-133.

- y Grupo VAL.Es.Co. (2002): Corpus de conversaciones coloquiales. Anejo de la Revista Oralia, Madrid: Arco/Libros.

- (coords.) (1995): La conversación coloquial (Materiales para su estudio). Anejo XVI de la Revista Cuadernos de Filología, Universidad de Valencia. 
Chimeno, S. (2004): «Información sobre salud, sanidad y medicina». En Javier Fernández del Moral (coord.), Periodismo especializado, Barcelona: Ariel Comunicación, 433-451.

Cortés Rodríguez, Luis (2012): «Los límites del discurso: condicionantes y realizaciones», Círculo de Lingüistica Aplicada a la Comunicación 51, 3-49.

Eguizábal, Raúl (1998): Historia de la Publicidad, Madrid: Eresma \& Celeste.

Fernández Colomer, M. J José y Marta Albelda Marco (2002): «Metáfora e intensificación». En Fernando Sánchez Miret (ed.), Actas del XXIII Congreso Internacional de Lingüistica y Filología Románica II/1, Tubinga: Niemeyer, 3-8.

FERNÁNDEZ GómEz, Jorge D. (2005): «Eslóganes, jingles y otras frases felices». En M. ${ }^{a}$ Victoria Romero Gualda (coord.), Lenguaje publicitario. La seducción permanente, Barcelona: Ariel, 89-112.

FERNÁNDEZ Lagunilla, Marina (1999): La lengua en la comunicación política II: La palabra del poder, Madrid: Arco/Libros.

Figueroa Bermúdez, Romeo A. (1999): Cómo hacer publicidad: un enfoque teóricopráctico, México: Pearson Education.

Fuentes RodRíguez, Catalina (1995): «Modalidad y conexión en el español coloquial», Español Actual 63, 5-24.

GARCÍA UCEDA, Mariola (1999): Las claves de la publicidad, Madrid: ESIC editorial.

GARRIDO LORA, Manuel (2000): El eslogan del año 2000, Questiones publicitarias 8, 68-87.

GARRIDO MEdina, Joaquín (1999): «Los actos de habla. Las oraciones imperativas». En Ignacio Bosque y Violeta Demonte (dirs.), Gramática descriptiva de la lengua española, Madrid: Real Academia Española y Espasa-Calpe, 3879-3928.

GONZÁlEZ BoRJA, Antonia (2004): «Salud, información periodística especializada en alza», Ámbitos 11-12, 301-310.

Gülich, Elisabeth y Tomás Kostchi (1995): «Discourse Production in oral Communication. A study based on French», Research in Text Theory 21, 30-66.

GuTIÉRREZ ORDóÑEz, Salvador (1997 [2000]): Comentario pragmático de textos publicitarios, Madrid: Arco/Libros.

HAVERKATE, Henk (1994): La cortesía verbal. Estudio pragmalingüístico, Madrid: Gredos.

Heritage, John (2002): «The Limits of Questioning: Negative Interrogatives and Hostile Question Content», Journal of Pragmatics 34, 1427-1446.

Herreros, Mario (1989): Teoría y Técnica de la Propaganda Electoral (Formas Publicitarias), Barcelona: ESRP-PPU.

Huici Módenes, Adrián (1994): «Propaganda y publicidad política: algunas cuestiones terminológicas», Questiones publicitarias 3, 98-104.

- (1996): Estrategias de la persuasión. Mito y propaganda política, Sevilla: Alfar Universidad.

- y Antonio Pineda Cachero (2004): «Introducción. La propaganda y sus medios». En Adrián Huici Módenes y Antonio Pineda Cachero (eds.), Propaganda y comunicación. Una aproximación plural, Sevilla: Comunicación Social, 9-12.

Kotlter, Philiph y Eduardo RoBerto (1992): Marketing social. Estrategias para cambiar la conducta pública, Madrid: Editorial Díaz de Santos.

LABRADOR GUTIÉRREZ, Tomás (2004): «Actos de cortesía negativa: juramentos, votos y blasfemias», Káñina, Revista de Arte y Letras XXVIII/2, 147-160. 
LAKOFF, George (1996): Moral Politics. What Conservatives Know that Liberals don't, Chicago: University of Chicago Press.

- (2004): Don't Think of an Elephant, Know Your Values, Frame the Debate, Chelsea: Green Publishing. (En español, No pienses en un elefante. Lenguaje y debate político, Madrid: Editorial Complutense 2007).

- (2008a): Puntos de inflexion, Manual del progresista, Barcelona: Península.

- (2008b): The Political Mind. A Cognitive Scientist's Guide to your Brain and its Politics, London: Penguin Books.

LÓPEZ SERENA, Araceli (2007): «El concepto de 'español coloquial': vacilación terminológica e indefinición del objeto de estudio», Oralia 10, 167-191.

- (2014): «De la oralidad fingida a la oralidad simuladora de realidad: reflexiones en torno a la coloquialización del discurso como estrategia mediática», Español Actual 102, 37-75.

LóPeZ Vilafranca, Paloma (2015): «Análisis de las campañas de comunicación de pacientes con enfermedades raras en España», Opción 31/5, 1042-1059.

Martín Zorraquino, M. ${ }^{a}$ Antonia y José Portolés LÁzaro (1999): «Los marcadores del discurso». En Ignacio Bosque y Violeta Demonte (dirs.), Gramática descriptiva de la lengua española, Madrid: Real Academia Española y EspasaCalpe, 4051-4214.

Méndez García de Paredes, Elena y Elena Leal Abad (2007): «La oralidad en el ámbito de los informativos». En Luis Cortés Rodriguez et al. (eds.), Discurso y oralidad, Homenaje al profesor José J. De Bustos Tovar, Madrid: Arco/Libros, 595608.

Méndiz Noguero, Alfonso (2008): «Diferencias conceptuales entre publicidad y propaganda: una aproximación etimológica», Questiones Publicitarias 1/12, 43-61.

NetTel, Ana L. y Georges RoQue (2012): «Persuasive Argumentation versus Manipulation», Argumentation 26/1, 55-69.

PAYRATó, Lluis (1990 [1988]): Català colloquial. Aspectes de l'us corrent de la llengua catalana, Valencia: Universitat de València.

Pineda Cachero, Antonio (2007a): «Propaganda y publicidad comercial: un principio diferenciador», Questiones publicitarias 1/12, 107-128.

- (2007b): «¿Todo es propaganda? El panpropagandismo o monismo propagandístico como límite superior de la teoría de la propaganda», Comunicación 5, 415-436.

Portero Muñoz, Carmen (1997): Intensificación: estudio de un clasema, Tesis Doctoral, Universidad de Córdoba.

Real Academia Española y Asociación de Academias de la lengua esPañola (2014 [2019]): Diccionario de la lengua española, Madrid: Espasa. $<$ https://dle.rae.es $>$.

REY, Juan (coord.) (1999): Comunicación política electoral. Elecciones municipales de Sevilla en 1999, Sevilla: Maecei.

- (ed.) (2005): Propaganda electoral. Elementos publicitarios y estrategias comunicativas en las elecciones municipales de Sevilla en 2003, Sevilla: Maecei.

Rivarola, José Luis (1984): «¿Quién es nosotros?», ELUA 2, 201-206.

Robles Ávila, Sara (2004): Realce y apelación en el lenguaje de la publicidad, Madrid: Arco/Libros. 
- (2005a): «Consideraciones sobre el léxico de la publicidad». En Sara Robles Ávila (edit.), Aspectos y Perspectivas del Lenguaje de la Publicidad, Analecta Malacitana, anejo LVI, 127-146.

- (2005b): «La recreación de lo coloquial en el español de la publicidad», Analecta Malacitana 27/2, 541-586.

- (2005c): «Sintaxis publicitaria II». En M. ${ }^{a}$ Victoria Romero Gualda (coord.), Lenguaje publicitario. La seducción permanente, Barcelona: Ariel, 225-256.

- (2007): «Los argumentos de la publicidad», Español Actual 87, 77-110.

- (2009): «El lenguaje publicitario en el español del turismo». En M. ${ }^{a}$ Cándida Muñoz Medrano (coord.), Enseñanza del español como L2. Contrastividad y registros lingüisticos, Catania: Flavius.

Romero Gualda, M. ${ }^{a}$ Victoria (2006): «Adjetivación sintáctica en textos publicitarios», Español Actual 86, 139-151.

SÁnchez Guzmán, José R. (1995): Promoción en marketing, Madrid: McGraw-Hill.

SÁnCHEZ-HERnándeZ, Francisco (2016): "Análisis sobre los contenidos de enfermedades raras en la prensa escrita española», Revista Española de Comunicación en Salud 7/2, 242-260.

SÁNCHEz López, Cristina (1999): «Los cuantificadores I. Sus clases, las estructuras cuantificativas». En Ignacio Bosque y Violeta Demonte (dirs.), Gramática descriptiva de la lengua española, Madrid: Real Academia Española/Espasa-Calpe, 1025-1128.

SANTIAGo Guervós, Javier (2008): «La selección léxica en la comunicación persuasiva: manipulación y uso del significado para la decodificación y la inferencia», Español Actual 89, 111-122.

SCRETI, Francisco (2011): «Publicidad y propaganda: terminología, ideología, ingenuidad», Razón y palabra 78. <http://www.razonypalabra.org.mx/varia/ N78/2a\%20parte/40_Screti_V78.pdf>.

SEARLE, John (1969 [1990]): Actos de habla, Cambridge: Cambridge University Press y Ediciones Cátedra,

SEFchovich, Sara (2014): «Los conflictos sociales como conflictos discursivos», Cultura y representaciones sociales, 9/17, 110-148.

SONTAG, Susan (2003): La enfermedad y sus metáforas. El sida y sus metáforas, Madrid: Suma de Letras.

Taube Horowitz, Gerardo (2001): «Análisis comparativo de los mensajes publicitarios hablados y cantados», en Discovery Network. <https://www.adlatina.com/ articulo.php?slug=/publicidad/análisis-comparativo-de-los-mensajes-publici tarios-hablados-y-cantados $>$.

VAn Dijk, Teun (2009): Discurso y poder. Contribuciones a los estudios críticos del discurso, Barcelona: Editorial GEDISA.

Vigara TAuste, Ana M. ${ }^{a}$ (1996): «Español coloquial: expresión del sentido por aproximación». En Thomas Kotschi, Wulf Oesterreicher y Klaus Zimmerman (coords.), El español hablado y la cultura oral en España e Hispanoamérica, Madrid: Vervuert/Iberoamericana, 15-44.

- (2000): «Sobre deixis coloquial», Círculo de Lingüistica Aplicada a la Comunicación 1 . <https://webs.ucm.es/info/circulo/nol/vigara.htm>. 


\section{APÉNDICE \\ RELACIÓN DE VÍDEOS QUE CONFORMAN EL CORPUS DE ANÁLISIS}

1. Paco Sanz Síndrome de Cowden.

2. Se puede decir tanto.

3. Mi primer montaje.

4. Lucha por la vida.

5. Esperanza es sobrevivir.

6. Grito de rabia.

7. Semper fi.

8. Marzo 28, 2014.

9. Retos en la vida.

10. Un ejemplo a seguir.

11. 17 de septiembre.

12. Explicación libro Paco Sanz.

13. Llamada auxilio.

14. Especial 20000 seguidores.

15. Firma y reflexión.

16. Sí a la vida.

17. Esperanza.

18. Presentación libro y reflexión.

19. Semana grande.

20. Mañana y reflexión.

21. Reflexión sobre la vida.

22. Help.

23. He vuelto para quedarme.
24. Cómo afrontar una enfermedad.

25. Amenazas de muerte.

26. ¿Me muero?

27. Soñando con la muerte.

28. Dolor.

29. Ácido sulfúrico.

30. Reflexión sobre la vida.

31. Regala vida estas Navidades.

32. Gracias por estar a mi lado.

33. Feliz Navidad, familia.

34. Reflexión de una noche de miedo.

35. Feliz año 2016.

36. Esta madrugada hará 6 años.

37. Por la vida vienes y te vas sin ruido.

38. Prueba de riesgo.

39. Vlog arteriografía.

40. Reflexión desde el corazón.

41. Decepción.

42. Felicidad, ¿dónde estás?

43. Canal secundario.

44. Comentarios inapropiados.

45. Personas insolidarias.

46. Vuelve la esperanza. 